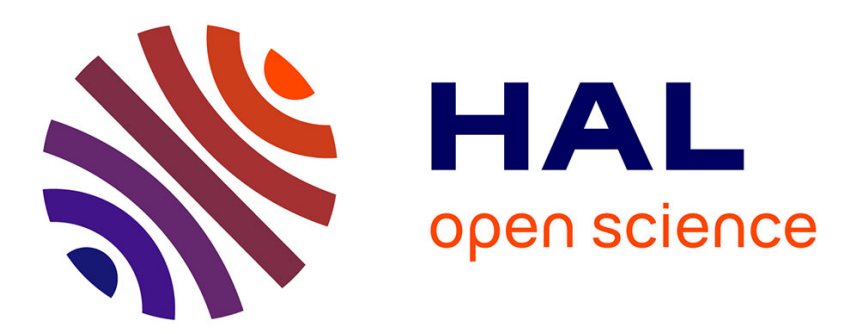

\title{
Accessing the Two-Electron Charge Storage Capacity of MnO2 in Mild Aqueous Electrolytes
}

Mickaël Mateos, Nikolina Makivic, Yee-seul Kim, Benoît B Limoges, Véronique Balland

\section{- To cite this version:}

Mickaël Mateos, Nikolina Makivic, Yee-seul Kim, Benoît B Limoges, Véronique Balland. Accessing the Two-Electron Charge Storage Capacity of MnO2 in Mild Aqueous Electrolytes. Advanced Energy Materials, 2020, pp.2000332. 10.1002/aenm.202000332 . hal-02566126

\section{HAL Id: hal-02566126 \\ https://hal.science/hal-02566126}

Submitted on 6 May 2020

HAL is a multi-disciplinary open access archive for the deposit and dissemination of scientific research documents, whether they are published or not. The documents may come from teaching and research institutions in France or abroad, or from public or private research centers.
L'archive ouverte pluridisciplinaire HAL, est destinée au dépôt et à la diffusion de documents scientifiques de niveau recherche, publiés ou non, émanant des établissements d'enseignement et de recherche français ou étrangers, des laboratoires publics ou privés. 


\title{
Accessing the two-electron charge storage capacity of $\mathrm{MnO}_{2}$ in mild aqueous electrolytes
}

Mickaël Mateos, Nikolina Makivic, Yee-Seul Kim, Benoît Limoges, * Véronique Balland*

Laboratoire d'Electrochimie Moléculaire, Université de Paris, UMR CNRS 7591, 15 rue

Jean-Antoine de Baïf, Paris F-75205 cedex 13, France.

E-mail: limoges@u-paris.fr, veronique.balland@u-paris.fr

\begin{abstract}
Rechargeable batteries based on $\mathrm{MnO}_{2}$ cathodes, able to operate in mild aqueous electrolytes, have attracted remarkable attention due to their appealing features for the design of low-cost stationary energy storage devices. However, the charge/discharge mechanism of $\mathrm{MnO}_{2}$ in such media is still unclear and a matter of debate. Here, an in-depth quantitative spectroelectrochemical analysis of $\mathrm{MnO}_{2}$ thin-films provides a set of important new mechanistic insights. A major finding is that charge storage occurs through the reversible twoelectron faradaic conversion of $\mathrm{MnO}_{2}$ into water-soluble $\mathrm{Mn}^{2+}$ in the presence of a wide range of weak Brønsted acids, including the $\left[\mathrm{Zn}\left(\mathrm{H}_{2} \mathrm{O}\right)_{6}\right]^{2+}$ or $\left[\mathrm{Mn}\left(\mathrm{H}_{2} \mathrm{O}\right)_{6}\right]^{2+}$ complexes commonly present in aqueous $\mathrm{Zn} / \mathrm{MnO}_{2}$ batteries. Furthermore, it is evidenced that buffered electrolytes loaded with $\mathrm{Mn}^{2+}$ are ideal to achieve highly reversible conversion of $\mathrm{MnO}_{2}$ with both high gravimetric capacity and remarkably stable charging/discharging potentials. In the most favorable case, a record gravimetric capacity of $450 \mathrm{~mA} \cdot \mathrm{h} \cdot \mathrm{g}^{-1}$ was obtained at a high rate of $1.6 \mathrm{~A} \cdot \mathrm{g}^{-1}$, with a coulombic efficiency close to $100 \%$ and $\mathrm{MnO}_{2}$ utilization of $84 \%$. Overall, the present results challenge the common view on $\mathrm{MnO}_{2}$ charge storage mechanism in mild aqueous electrolytes and underline the benefit of buffered electrolytes for high-performance rechargeable aqueous batteries.
\end{abstract}




\section{Introduction}

Over the past few decades, manganese dioxide $\left(\mathrm{MnO}_{2}\right)$ cathodes attracted increasing attention due to their low cost, environmental friendliness, high theoretical gravimetric capacity (i.e., $617 \mathrm{~mA} \cdot \mathrm{h}^{-\mathrm{g}^{-1}}$ considering the $2 \mathrm{e}^{-}$transfers from $\mathrm{Mn}^{\mathrm{IV}}$ to $\mathrm{Mn}^{\mathrm{II}}$ ), and high reduction potential in water. These features make them attractive for the large scale development of inexpensive, eco-sustainable, and energy-dense rechargeable aqueous batteries, suitable for electricity storage produced from renewable and intermittent energy sources. ${ }^{[1-4]}$ Commonly used primary alkaline batteries, where electrolytic $\mathrm{MnO}_{2}$ is paired with a zinc anode in a concentrated $\mathrm{KOH}$ electrolyte, are well-recognized for their ability to deliver high-energy densities (ranging from 80 to $190 \mathrm{~W} \cdot \mathrm{h} \cdot \mathrm{kg}^{-1}$ ) but can only be discharged once because of irreversible changes in the $\mathrm{MnO}_{2}$ structure. ${ }^{[5]}$ Their discharge is also limited to the first electron reduction of $\mathrm{MnO}_{2}$ to $\mathrm{MnOOH}$, resulting in a loss of energy density. Limiting the depth-of-discharge to 5-10\% of the maximal capacity of $\mathrm{MnO}_{2}$ was shown as a valuable strategy to convert primary $\mathrm{Zn} / \mathrm{MnO}_{2}$ alkaline batteries into rechargeable ones (over $1,000-3,000$ cycles), but at the expense of an energy density reduced to $25-35 \mathrm{~W} \cdot \mathrm{h} \cdot \mathrm{kg}^{-1} \cdot{ }^{[6]}$ It is only recently that a full and reversible access to the two electron capacity of $\mathrm{MnO}_{2}$ has been demonstrated. ${ }^{[7],[8,9]}$ However, this was achieved for extreme $\mathrm{pH}$ values, i.e. either in strongly basic or acidic electrolytes. Under strong basic conditions (37 wt\% $\mathrm{KOH})$, the reversible cycling between $\mathrm{MnO}_{2}$ and $\mathrm{Mn}(\mathrm{OH})_{2}$ was shown with $80-100 \%$ utilization of the $617 \mathrm{~mA} \cdot \mathrm{h} \cdot \mathrm{g}^{-}$

${ }^{1}$ over 6000 cycles. ${ }^{[7]}$ This was made possible thanks to the addition of $\mathrm{Bi}_{2} \mathrm{O}_{3}$ and $\mathrm{Cu}$ to the electrode's mix, which both enable the reaction by reducing the charge transfer resistance, preventing the hausmannite $\left(\mathrm{Mn}_{3} \mathrm{O}_{4}\right)$ formation, and favoring the regeneration of $\mathrm{MnO}_{2}$ from $\mathrm{Mn}(\mathrm{OH})_{2} \cdot{ }^{[7]}$ To the other end of the $\mathrm{pH}$ scale, reversible cycling between $\mathrm{MnO}_{2}$ and soluble $\mathrm{Mn}^{2+}$ was demonstrated in 0.1 to $0.3 \mathrm{M} \mathrm{H}_{2} \mathrm{SO}_{4}$ over a few thousand cycles according to a 
reversible electrodeposition-electrodissolution conversion mechanism. ${ }^{[8,9]}$ Nevertheless, such extreme $\mathrm{pH}$ conditions are not ideal for the design of large-scale energy storage systems, notably because of corrosion issues which reduce the durability of the system and potentially lead to safety concerns. For these reasons, the development of $\mathrm{MnO}_{2}$-based rechargeable batteries operating under mild aqueous conditions is desirable. This has prompted many groups in the recent years to develop the concept of rechargeable $\mathrm{Zn} / \mathrm{MnO}_{2}$ batteries in neutral or slightly acidic aqueous electrolytes ( $\mathrm{pH} 3-6$ ), containing a few molar $\mathrm{ZnSO}_{4}$ and $0.1-0.3 \mathrm{M}$ $\mathrm{MnSO}_{4} \cdot{ }^{[10-25]}$ While the beneficial effect of adding $\mathrm{Mn}^{2+}$ in the electrolyte was initially shown in 1998 by Kim and Oh, ${ }^{[26]}$ the demonstration that it can considerably improve the cycling stability of a $\mathrm{Zn} / \mathrm{MnO}_{2}$ battery was only recently reported, ${ }^{[10]}$ allowing to achieve at $\alpha-\mathrm{MnO}_{2}$ nanofibers a capacity retention $\left(\sim 150 \mathrm{~mA} \cdot \mathrm{h} \cdot \mathrm{g}^{-1}\right)$ of $92 \%$ over 5000 cycles. Similar high performances were thereafter reached by other groups with a variety of $\mathrm{MnO}_{2}$ structures and electrode architectures. ${ }^{[27]}$

Despite these significant advances, the $\mathrm{MnO}_{2}$ discharge/charge mechanism is still unclear and a matter of debate, notably regarding the chemical nature of the inserting cation and the exact role of preadded $\mathrm{Mn}^{2+}$ in the cycling improvement. Different charge storage mechanisms were indeed proposed. A majority of works rely on the assumption of reversible Zn-ion insertion (or intercalation) into $\mathrm{MnO}_{2}$ to produce either layered $\mathrm{Zn}$-birnessite, $\mathrm{Zn}$ buserite, or spinel $\mathrm{ZnMn}_{2} \mathrm{O}_{4} \cdot{ }^{[11-13,18,21,23,25,28-30]}$ In other studies, the authors claim that both $\mathrm{H}^{+}$ and $\mathrm{Zn}^{2+}$ co-intercalate within $\mathrm{MnO}_{2}$ but along to different thermodynamic paths and chemical reactions. ${ }^{[15-17,22,31,32]}$ Finally, a few studies report on an exclusive proton uptake to form either $\mathrm{MnOOH}^{[10,14,26,33]}$ or soluble $\mathrm{Mn}^{2+}$ (with simultaneous precipitation of zinc hydroxide sulfates induced by local $\mathrm{pH}$ increase), ${ }^{[34]}$ but without demonstrating where protons come from. 
Another critical issue is the moderate gravimetric capacities reported in these studies, ranging from 220 to $370 \mathrm{~mA} \cdot \mathrm{h} \cdot \mathrm{g}^{-1},{ }^{[27]}$ corresponding roughly to half of the maximal theoretical capacity of $\mathrm{MnO}_{2}$. This led several groups to conclude that the reversible discharge mechanism is circumscribed to a one-electron reduction of $\mathrm{Mn}^{\mathrm{IV}} \mathrm{O}_{2}$ into different $\mathrm{Mn}^{\mathrm{III}}$ species such as $\mathrm{Mn}^{\mathrm{III}} \mathrm{OOH}^{[10,14,22,31]}$ or $\mathrm{Zn}$-intercalation products. ${ }^{[1,17,18,22,31]}$ However, it remains difficult to conceive that $\mathrm{MnO}_{2}$ reduction is restricted to a single-electron process, especially when dissolution to $\mathrm{Mn}^{2+}$ is frequently observed upon discharging $\mathrm{MnO}_{2}{ }^{[10,11,21,31,34,35]}$ (thus necessarily involving a two electron reduction of $\mathrm{MnO}_{2}$ into $\mathrm{Mn}^{2+}$, whether the latter is generated directly by electrochemical reduction or indirectly from disproportionation of the intermediate $\mathrm{Mn}^{\mathrm{III}}$ species). Futhermore, the single electron hypothesis cannot explain the beneficial role of preadded $\mathrm{Mn}^{2+}$. In several studies it is reported that $\mathrm{Mn}^{2+}$ help to suppress, ${ }^{[10,11]}$ inhibit, ${ }^{[12]}$ or discourages ${ }^{[26]}$ Mn dissolution, with the underlying assumption that it changes the equilibrium of $\mathrm{Mn}$ dissolution from the $\mathrm{MnO}_{2}$ electrode ${ }^{[10]}$ However, this reasoning is hard to follow given that the preadded concentration of $\mathrm{Mn}^{2+}$ remains low $(0.1-0.3 \mathrm{M})$ and thus far from saturation. ${ }^{[36]}$

A main consequence of the aforementioned mechanistic doubts and inconsistencies is that the corresponding balanced equation is uncertain, precluding thus the rational design and optimization of mild aqueous $\mathrm{Zn} / \mathrm{MnO}_{2}$ batteries. The purpose of the present work is to fill this gap by performing an in-depth quantitative analysis of the electrochemical charge/discharge mechanism occurring at pure $\mathrm{MnO}_{2}$ films in various aqueous electrolytes. To this end, well-defined and reproducible $\mathrm{MnO}_{2}$ thin-films anodically electrodeposited on flat ITO electrodes were used. These $\mathrm{MnO}_{2}$ electrodes have the advantage to avoid polymer binder and carbon additives. Moreover, their semi-transparency allows for their quantitative characterization by UV/vis spectroelectrochemistry, a methodology we previously used to investigate the proton-coupled electron charge storage at nanostructured $\mathrm{TiO}_{2}$ electrodes. ${ }^{[37,38]}$ In the present case, spectroelectrochemical analysis offers the additional opportunity to 
quantify in-situ the amount of $\mathrm{MnO}_{2}$ on the electrode, allowing for real-time monitoring the active material that dissolves and redeposits along the discharging/charging cycles. In order to deconvolute the exact role of the different chemical species contained in the electrolyte, the electrodes were cycled in buffered and unbuffered aqueous electrolytes of different nature, composition, and $\mathrm{pH}$. Our results unambiguously demonstrate that, under mild aqueous conditions, the nearly two-electron storage capacity of $\mathrm{MnO}_{2}$ is accessible when a weak Brønsted acid is present at a sufficiently high concentration. This latter act as the essential source of protons required for the easy and reversible dissolution of $\mathrm{MnO}_{2}$ into soluble $\mathrm{Mn}^{2+}$.

\section{Results and Discussion}

The $\mathrm{MnO}_{2}$ thin-film electrodeposited on the ITO electrode (see Experimental Section) was characterized by SEM, XRD, XPS and UV-vis absorption spectroscopy as detailed in the SI. The amorphous film exhibits a typical sheetlike nanostructure with a large surface/electrolyte interface. A major feature of the film is the average redox state of the Mn ions, which was estimated to 3.7 from both XPS and ICP quantification. Accordingly, the maximal theoretical gravimetric capacity of the as-deposited $\mathrm{MnO}_{2}$ thin film is $571 \mathrm{~mA} \cdot \mathrm{h} \cdot \mathrm{g}^{-1}$.

\subsection{Capacitive behavior in unbuffered aqueous $\mathrm{KCl}$ electrolyte, pH 5.0}

The as-electrodeposited $\mathrm{MnO}_{2}$ thin films were first investigated by UV-vis spectroelectrochemistry in a $1 \mathrm{M} \mathrm{KCl}$ electrolyte adjusted to $\mathrm{pH} 5.0\left(\left[\mathrm{H}_{3} \mathrm{O}^{+}\right] \sim 10^{-5} \mathrm{M}\right)$. The simultaneously recorded cyclic voltammograms (CVs) and cyclic voltabsorptograms (CVAs), as well as the galvanostatic charging/discharging curves concomitantly monitored by potentiometry and UV-vis absorptometry are shown in Figure 1. Both the shape and the stability of the quasi-rectangular $\mathrm{CV}$ and the $\mathrm{V}$-shaped galvanostatic curves support the reversible charging of an electrical double layer at the $\mathrm{MnO}_{2} /$ electrolyte interface. ${ }^{[39]}$

In the $\mathrm{CV}$, the magnitude of the $\mathrm{MnO}_{2}$ capacitive current is considerably higher than the one recorded at the bare ITO electrode (Figure 1A). This point illustrates the remarkable 
ability of $\mathrm{MnO}_{2}$ film to boost the overall capacitance of the electrode, which makes it of great interest for the development of supercapacitors. ${ }^{[40-53]}$ The apparent specific gravimetric capacitance of the $\mathrm{MnO}_{2}$ film was $C_{f}=270 \mathrm{~F} \cdot \mathrm{g}^{-1}$ at a rate of $0.15 \mathrm{~mA} \cdot \mathrm{cm}^{-2}\left(14 \mathrm{~A} \cdot \mathrm{g}^{-1}\right)$, which lies within the range of capacitances commonly reported for $\mathrm{MnO}_{2}$ thin films, electrodeposited on planar electrodes. ${ }^{[40,41,45-47]}$ A higher value of $390 \mathrm{~F} \cdot \mathrm{g}^{-1}$ was obtained by decreasing twice the discharging rate to $0.075 \mathrm{~mA} \cdot \mathrm{cm}^{-2}$. Such a rate effect was frequently reported but only recently elucidated as the consequence of the ohmic potential drop, ${ }^{[54]}$ generated here across the poorly conductive film of $\mathrm{MnO}_{2}$.

In the galvanostatic experiments, the absence of fading upon continuous cycling reveals excellent reversibility and stability, with nearly $100 \%$ coulombic efficiency (Figure 1C). Such a high stability supports the hypothesis of a stable Mn oxidation state upon cycling (at least within the potential window 0 to $0.95 \mathrm{~V}$, otherwise it would lead to a gradual capacity decrease, resulting either from the gradual faradaic dissolution of the film ${ }^{[48]}$ or from the conversion of $\mathrm{MnO}_{2}$ into less electrochemically active manganese species, ${ }^{[49]}$ which is typically what happens when a $\mathrm{MnO}_{2}$ electrode is polarized at too negative potential values ${ }^{[50]}$ ). This was confirmed by $e x$-situ XPS characterization of the electrode at the end of a first galvanostatic discharge to $0 \mathrm{~V}$ in $1 \mathrm{M} \mathrm{KCl}$ (Table S1). Contrary to what has been previously published, ${ }^{[44]}$ the XPS Mn(3s) peak splitting $(4.63 \mathrm{eV})$ was practically unchanged compared to the as-electrodeposited $\mathrm{MnO}_{2}$ film (4.64 eV), demonstrating no noticeable redox changes at the Mn centers. This is fully consistent with the in situ Mn K-edge XAS analyses of electrodeposited $\mathrm{MnO}_{2}$ films, ${ }^{[49]}$ showing only a small fluctuation in the Mn oxidation state in a similar potential window. Finally, we notice that the galvanostatic charging/discharging cycles remain almost unchanged once the $\mathrm{MnO}_{2}$ electrode is successively immersed in an aqueous electrolyte containing $1 \mathrm{M} \mathrm{KCl}, 1 \mathrm{M} \mathrm{NaCl}$ or $1 \mathrm{M} \mathrm{LiCl}$ (all adjusted to $\mathrm{pH}$ 5) (see Figure S1). Such a behavior demonstrates a charge storage mechanism relatively indifferent to 
the nature, size and solvation of the cation, attesting thus of a conventional double layer capacitance. All these observations are consistent with those extensively reported for $\mathrm{MnO}_{2}$ electrodes in mild aqueous electrolytes containing just an inert salt. ${ }^{[42,43,51-53]}$

With regard to the electrochromic properties of $\mathrm{MnO}_{2}$, both the CVAs and the absorptometric traces recorded during the galvanostatic cycles show an almost linear absorbance change as a function of the applied potential, as well as a fully reversible change upon switching back to the starting potential. The absorbance variation stays significant $(|\Delta A| \sim 0.1)$ within the potential window investigated here $(0-0.95 \mathrm{~V})$. It most likely results from a capacitive effect, as demonstrated for other metal oxide semiconductors in the absence of ion intercalation, ${ }^{[55,56]}$ notably for $\mathrm{TiO}_{2} \cdot{ }^{[37,57]}$ It is worth noting that the potential window investigated here lies within the conduction band of $\mathrm{MnO}_{2},{ }^{[58]}$ so it behaves as an ohmic conductor which Fermi level is governed by the underlying ITO potential. The density of delocalized charge carriers in $\mathrm{MnO}_{2}$ is consequently modulated through the filling of the conduction band by charge injection from ITO. This electron doping thus induces a change in the $\mathrm{MnO}_{2}$ absorbance with an almost linear correlation with the applied potential.

Finally, all of the present results demonstrate that the electrodeposited $\mathrm{MnO}_{2}$ thin film behaves as an electrical double layer capacitor when cycled in an aqueous electrolyte containing only an inert alkali cation and a negligible amount of free protons $\left(\left[\mathrm{H}_{3} \mathrm{O}^{+}\right] \sim 10^{-5}\right.$ M).

\subsection{Faradaic $\mathrm{MnO}_{2}$ conversion in the presence of weak acids at pH 5}

Next, we investigated the electrochemical behavior of $\mathrm{MnO}_{2}$ thin films in a $1 \mathrm{M}$ acetate buffer of $\mathrm{pH} 5.0$, along with $0.3 \mathrm{M} \mathrm{KCl}$ to maintain the same ionic strength as above. Under these conditions, the concentration of free protons remains low, i.e. $\left[\mathrm{H}_{3} \mathrm{O}^{+}\right]=10^{-5} \mathrm{M}$. The only difference compared to previous conditions is the presence of a weak Brønsted acid with its conjugate base, i.e. the acetic acid $(0.25 \mathrm{M})$ and sodium acetate $(0.75 \mathrm{M})$, 
characterized by a $\mathrm{p} K_{\mathrm{a}}$ of 4.76 . The experimental data reported in Figure 2 demonstrate a radically different electrochemical behavior of $\mathrm{MnO}_{2}$ in such buffered electrolyte compared to that obtained in unbuffered $1 \mathrm{M} \mathrm{KCl}$ at the same $\mathrm{pH}$ (compare the dashed and plain black lines in Figure 2A).

In the $\mathrm{CV}$ experiment (Figure 2A), on top of the capacitive current a very intense, sharp and well-defined faradaic reduction peak located at $0.47 \mathrm{~V}$ is observed during the first reduction scan. Its integration leads to a total charge of $16 \mathrm{mC} \cdot \mathrm{cm}^{-2}$. (Integration over the entire potential window leads to a slightly higher value of $20.5 \mathrm{mC} \cdot \mathrm{cm}^{-2}$, accounting for the additional contribution of the double layer capacitance of $\mathrm{MnO}_{2}$ ). Concomitantly to the faradaic peak, the magnitude of the electrode absorbance is drastically decreased. This faradaic reduction is also irreversible owing to the absence of reoxidation peak in the reverse $\mathrm{CV}$ scan and to the continuous decrease of current and absorbance in the further CV and CVA cycles, respectively. Such behavior strongly suggests the reductive dissolution of the $\mathrm{MnO}_{2}$ film, a faradaic process manifestly induced here by the acetate buffer.

In echoes to the CVs, the galvanostatic experiments (Figure 2B) show during the first discharge a well-defined single faradaic plateau centered on an average potential of $0.56 \mathrm{~V}$ with a concomitant strong electrode absorbance decrease $(\Delta A \sim-0.17$, which cannot be attributed to $\mathrm{MnO}_{2}$ electrochromism because of the constant potential value). The total charge of $15 \mathrm{mC} \cdot \mathrm{cm}^{-2}$ (nearly the same than from the peak integration in $\mathrm{CV}$ ) corresponds to a gravimetric capacity of $404 \mathrm{~mA} \cdot \mathrm{h} \cdot \mathrm{g}^{-1}$ based on the initial mass of $\mathrm{MnO}_{2}$, which indicates that more than one electron is passed per Mn center. The subsequent charging/discharging cycles are characterized by a fast fading of both the discharge capacity and electrode absorbance down to residual threshold values, signing thus again the faradaic $\mathrm{MnO}_{2}$ dissolution upon cycling. The amount of $\mathrm{MnO}_{2}$ remaining on the ITO surface after 5 galvanostatic cycles (Figure 2B, blue dot) was determined by ICP to be $2 \mu \mathrm{g} \cdot \mathrm{cm}^{-2}$, which represents $\sim 20 \%$ of the 
initial mass of $\mathrm{MnO}_{2}$. This outcome definitely confirms that the electrode fading results from (i) the rapid loss of $\mathrm{MnO}_{2}$ from the ITO surface according to a reductive faradaic process leading to soluble $\mathrm{Mn}^{2+}$, and (ii) the ineffectiveness of the back re-electrodeposition of $\mathrm{MnO}_{2}$ from the small amount of $\mathrm{Mn}^{2+}$ released in solution.

In order to better evidence the link between the faradaic reactivity and the buffer composition, a series of first galvanostatic discharges were recorded in electrolytes containing an increasing concentration of acetate buffer (from $1 \mathrm{mM}$ to $1 \mathrm{M}$ ), keeping the $\mathrm{pH}$ at 5.0. As expected, the discharge curves (Figure S2) show an increase of capacity (from 50 to 410 $\mathrm{mA} \cdot \mathrm{h} \cdot \mathrm{g}^{-1}$ ) with the increase of buffer concentration, along with a progressive transition from a capacitive behavior (characterized by a linear variation of the potential with time) to a faradaic discharge (characterized by a well-defined potential plateau). This behavior strongly supports a mechanism involving the weak Brønsted acidity of acetic acid. Indeed, at a sufficiently high buffer concentration, it can play the role of an efficient proton donor to assist the faradaic proton-coupled electron transfer reaction required for the dissolution of $\mathrm{MnO}_{2}$ into $\mathrm{Mn}^{2+}$. This is very analogous to what we recently demonstrated for the reversible insertion of protons in $\mathrm{TiO}_{2}$ in the presence of a weak acid. ${ }^{[37,38]}$ From these considerations, we can thus propose the following global proton-coupled electron transfer reaction at the metal oxide/electrolyte interface:

$$
\mathrm{MnO}_{2(\mathrm{~s})}+4 \mathrm{AH}+2 \mathrm{e}^{-} \leftrightarrows \mathrm{Mn}^{2+}{ }_{(\mathrm{aq})}+4 \mathrm{~A}^{-}+2 \mathrm{H}_{2} \mathrm{O}
$$

where $\mathrm{AH}$ and $\mathrm{A}^{-}$are the weak acid and conjugated base of the buffer, respectively. In absence of preadded $\mathrm{Mn}^{2+}$ in the electrolyte, reaction 2 is apparently irreversible, but we will show later on that full reversibility can be achieved in an appropriate buffered electrolyte.

The striking contrast we observe between buffered and unbuffered conditions perfectly highlights how the presence of a proton donor at an appropriate concentration is crucial to move from a purely capacitive behavior to an almost exclusive faradaic one. It is worth noting that even if the solvent is itself a weak Brønsted acid, $\mathrm{H}_{2} \mathrm{O}$ cannot induce reductive 
dissolution of $\mathrm{MnO}_{2}$ in the explored potential window because of thermodynamic considerations, as we will discuss later.

\subsection{Influence of the electrolyte composition on the first discharge of the $\mathrm{MnO}_{2}$ thin films}

\subsubsection{Effect of the addition of $\mathrm{Mn}^{2+}$ in the electrolyte.}

As mentioned in the introduction, addition of $\mathrm{Mn}^{2+}$ (at an optimal concentration ranging from 0.1 to $0.3 \mathrm{M}$ ) has been reported to significantly improve the rechargeability of $\mathrm{Zn} / \mathrm{MnO}_{2}$ aqueous batteries, ${ }^{10,[26], 27}$ but through a mechanism that so far has not been clearly established. ${ }^{[10-12,26]}$ Therefore, we examined the first galvanostatic discharge of an aselectrodeposited $\mathrm{MnO}_{2}$ electrode in an acetate buffer (1 M, pH 5.0) containing $0.1 \mathrm{M} \mathrm{MnCl}_{2}$. A well-defined single discharge plateau at an average potential of $0.52 \mathrm{~V}$ is obtained (Figure 2C, blue curve), leading after completion to a total discharge capacity of $385 \mathrm{~mA} \cdot \mathrm{h} \cdot \mathrm{g}^{-1}$. Concomitantly, the absorbance dropped by $\sim 0.16$. These data are very similar to those discussed above in the absence of preadded $\mathrm{Mn}^{2+}$ (compare the blue curves in Figure $2 \mathrm{C}$ to the black ones in Figure 2B). The discharged electrode, further characterized by ex-situ SEM and XPS, was then compared to both an as-electrodeposited $\mathrm{MnO}_{2}$ electrode and a bare ITO electrode (Figure 3). For the discharged electrode, a strong contribution of the underlying ITO surface is observed in the XPS spectrum (see also Table S1). This validates the dissolution of a large fraction of the $\mathrm{MnO}_{2}$ film, making discernible the underlying ITO, as also confirmed by SEM. Still, a small fraction of the film remains on the surface at the end of the first discharge, which is consistent with the light-yellow color of the discharged electrode (Figure 3B) and the non-zero value reached by $\Delta A$ (Figure 2C). Its further analysis by ex-situ XPS indicates an AOS of Mn almost identical to that of the initial film (Figure 3E and Table S1), suggesting that the $\mathrm{MnO}_{2}$ reductive dissolution occurs without noticeable accumulation of lower oxidation states of $\mathrm{Mn}$ at the electrode surface. We thus assume that the remaining film fraction still correspond to $\mathrm{MnO}_{2}$ but with a low electrical connection to the underlying 
electrode, impeding thus its efficient reductive dissolution. The residual amount of undissolved $\mathrm{MnO}_{2}$, estimated from both the electrode absorbance (using Equation S2) and ICP titration, was 20 wt. $\%$ of the initial film. Based on this quantitative analysis, the gravimetric capacity delivered by the redox-active fraction of $\mathrm{MnO}_{2}(\sim 80$ wt. \%) was estimated to $480 \mathrm{~mA} \cdot \mathrm{h} \cdot \mathrm{g}^{-1}$. This corresponds to an average number of 1.6 electron passed per dissolved $\mathrm{Mn}$ center, thus quite consistent with the $\mathrm{MnO}_{2}$ average oxidation state of 3.7 (determined by both ICP titration and XPS analysis, see SI for details).This result definitely confirms the electrochemical reduction of $\mathrm{MnO}_{2}$ (or more rigorously of $\mathrm{Mn}^{\mathrm{IV}}{ }_{0.72} \mathrm{Mn}^{\mathrm{III}}{ }_{0.28} \mathrm{O}_{2} \mathrm{~K}_{0.09} \mathrm{H}_{0.19}$, as reported in $\mathrm{SI}$ ) into the water-soluble $\mathrm{Mn}^{2+}$ species.

Overall, the above results demonstrate that, whether there is or not $\mathrm{Mn}^{2+}$ in the electrolyte, the $\mathrm{MnO}_{2}$ film undergoes similar massive reductive dissolution upon discharging in a $1 \mathrm{M}$ acetate buffer of $\mathrm{pH}$ 5.0. In contrast to what has been previously reported in the literature, this dissolution is neither suppressed, ${ }^{[10,11]}$ inhibited, ${ }^{[12]}$ or discouraged ${ }^{[26]}$ by the preadded $\mathrm{Mn}^{2+}$ in the electrolyte.

\subsubsection{Influence of the discharging rate and charge transfer resistance.}

The first galvanostatic discharges of as-electrodeposited $\mathrm{MnO}_{2}$ electrodes were recorded at different rates in a $1 \mathrm{M}$ acetate buffer ( $\mathrm{pH}$ 5.0) containing $0.1 \mathrm{M} \mathrm{MnCl}_{2}$ (Figure $\mathrm{S} 3)$. When the rate increases from 1 to $15 \mathrm{~A} \cdot \mathrm{g}^{-1}$, almost $100 \%$ of the gravimetric capacity is preserved (see also Table S2), while the discharge plateau potential is only downshifted by a few $\mathrm{mV}$. These observations demonstrate an excellent rate capability wherein $\mathrm{MnO}_{2}$ reductive dissolution is fast, occurring nearly at the thermodynamic equilibrium for discharge rates $<15$ $\mathrm{A} \cdot \mathrm{g}^{-1}$. Therefore, according to Equation 1, we can write an equilibrium potential governed by the following Nernst equation (valid at $25^{\circ} \mathrm{C}$ as long as $\mathrm{MnO}_{2}$ is present on the working electrode, see SI for details):

$$
E=E_{\mathrm{MnO}_{2} / \mathrm{Mn}^{2+}}^{0}-0.12 \times \mathrm{pH}-0.03 \times \log \left(a_{\mathrm{Mn}^{2+}}\right)
$$


where $E_{\mathrm{MnO}_{2} / \mathrm{Mn}^{2+}}^{\mathrm{i}}$ is the standard potential of the $\mathrm{MnO}_{2} / \mathrm{Mn}^{2+}$ redox couple defined at $\mathrm{pH} 0$ (i.e., $1.315 \mathrm{~V}$ vs. NHE for $\left.\gamma-\mathrm{MnO}_{2}{ }^{[59]}\right)$, and $a_{\mathrm{Mn}^{2+}}$ the activity of $\mathrm{Mn}^{2+}$ in solution. For the $1 \mathrm{M}$ acetate buffer containing $0.1 \mathrm{M} \mathrm{MnCl}_{2}$, the activity of $\mathrm{Mn}^{2+}$ can be estimated as 0.04 (calculated using the Truesdell-Jones equation ${ }^{[60]}$ ). Using this value in Equation 2, an equilibrium potential of $E=0.557 \mathrm{~V}$ (vs. $\mathrm{Ag} / \mathrm{AgCl}$ at $\mathrm{pH} 5.0$ ) can be predicted. This potential value is close to that obtained for the first discharge plateaus in Figure S3 (i.e., $\sim 0.52 \mathrm{~V}$ ), therefore confirming that the discharge process is close to the equilibrium at the slowest rates.

The first discharging process was also investigated by galvanostatic intermittent titration (GITT). First of all, the GITT plot (Figure 2C) shows a complete dissolution of the film after 22 pulses as attested by the final $\Delta A$ value of -0.014 and the total gravimetric capacity of $518 \mathrm{~mA} \cdot \mathrm{h} \cdot \mathrm{g}^{-1}$ (close to the maximal theoretical capacity of $524 \mathrm{~mA} \cdot \mathrm{h} \cdot \mathrm{g}^{-1}$ if assuming $1.7 \mathrm{e}^{-}$per $\mathrm{Mn}$ ), consistent with a complete dissolution of the $\mathrm{MnO}_{2}$ film. Analysis of the GITT discharge profile allows to clearly identify two distinct regions. A Region I, i.e. below $300 \mathrm{~mA} \cdot \mathrm{h} \cdot \mathrm{g}^{-1}$, where a stable discharge potential value centered on $0.5 \mathrm{~V}$ is rapidly reached after each pulse. This is associated to a steadily decrease of the absorbance (by step of $\sim 0.01$ absorbance unit per pulse). During the relaxation step, while the absorbance remains stable, the OCP relaxes to a constant equilibrium value of $0.54 \mathrm{~V}$, very close to the theoretical equilibrium potential calculated using Equation 2 (represented by the horizontal dotted line in Figure 2C). The small overvoltage observed in Region I is indicative of a low charge transfer resistance as well as of a fast electrochemical reductive dissolution of $\mathrm{MnO}_{2}$ into $\mathrm{Mn}^{2+}$, occurring thus nearly under thermodynamic equilibrium as discussed above. In Region II, a large voltage drop to ca. $-0.7 \mathrm{~V}$ is observed, together with an absorbance decrease similar to that in Region I, while the OCP continues to relax close to $0.54 \mathrm{~V}$, as in Region I. The constant equilibrium OCP recorded during the entire GITT experiment strongly agrees with 
the equilibrium potential defined by eq. 2 , which therefore solely depends on the $\mathrm{pH}$ and $\mathrm{Mn}^{2+}$ activity in solution.

In Region II, it is interesting to note that a new potential plateau is reached at $\sim-0.65$ $\mathrm{V}$, signing a new faradaic process we attribute to the electrochemical reduction of dioxygen into hydrogen peroxide. $\mathrm{H}_{2} \mathrm{O}_{2}$ is well known to chemically reduce $\mathrm{MnO}_{2}$, even under mild aqueous conditions. ${ }^{[61-63]}$ It can thus be assumed that the electrochemically generated $\mathrm{H}_{2} \mathrm{O}_{2}$ contributes to the chemical reductive dissolution of the residual $\mathrm{MnO}_{2}$ up to a complete dissolution. Further work is however required to definitely prove such reactivity.

\subsubsection{Influence of the buffer composition.}

According to Equation 2, the equilibrium discharge potential is expected to be a function of the local activity of $\mathrm{Mn}^{2+}$ and $\mathrm{pH}$, which means that any gradient of $\left[\mathrm{Mn}^{2+}\right]$ or $\mathrm{pH}$ at the electrode interface should influence the discharge electrode potential and so its evolution with time. In electrolytes containing $0.1 \mathrm{M} \mathrm{MnCl}_{2}$, the $\mathrm{Mn}^{2+}$ concentration locally released in the diffusion layer cannot significantly alter the already high local concentration of $\mathrm{Mn}^{2+}(0.1 \mathrm{M})$. This is supported by the following rough calculation. If we assume that the released $\mathrm{Mn}^{2+}$ diffuses $\left(D_{\mathrm{Mn}^{2+}}=7 \times 10^{-6} \mathrm{~cm}^{2} \cdot \mathrm{s}^{-1}\right)$ in solution according to a linear gradient across a constant natural diffusion-convection layer (that takes place after a few tens of seconds over a maximal thickness of $\sim 200 \mu \mathrm{m}^{[64]}$ ), we can estimate that the local increase of $\left[\mathrm{Mn}^{2+}\right]$ should not exceed $2.5 \mathrm{mM}$. This value is clearly negligible compared to the $0.1 \mathrm{M}$ $\mathrm{Mn}^{2+}$ initially presents. A similar reasoning can be applied to the local change of $\mathrm{pH}$, which in $1 \mathrm{M}$ buffered electrolyte cannot significantly vary.

The pH-dependence of the first discharge plateau potential was investigated in miscellaneous aqueous buffers of different pHs (ranging from 2.95 to 7.0 ) with $0.1 \mathrm{M} \mathrm{MnCl}_{2}$ (Figure 4). Special care was taken to maintain $[\mathrm{AH}]$ and $\left[\mathrm{A}^{-}\right]$in the same proportions to ensure no $\mathrm{pH}$ gradients (see Experimental Section for buffer compositions). Whatever the pHs 
and buffered electrolytes, the shapes and gravimetric capacities are well conserved (Figure 4A) unlike the average discharge plateau potential (or half-discharge potential) which scales linearly with the $\mathrm{pH}$, leading to a slope of $-125 \mathrm{mV} / \mathrm{pH}$ unit (Figure $4 \mathrm{C}$ ). This slope perfectly agrees with Equation 2.

Similar experiments were reproduced in the same buffers but without $\mathrm{MnCl}_{2}$, letting to explore the higher $\mathrm{pH}$ value of 9.1. ${ }^{[65]}$ The resulting discharge curves (Figure 4A) are systematically slightly up-shifted compared to those previously obtained in the presence of 0.1 $\mathrm{M} \mathrm{MnCl}_{2}$, including even a somewhat steeper discharge plateau. This is again consistent with Equation 2, predicting an increase of the equilibrium potential upon decreasing the $\mathrm{Mn}^{2+}$ activity. Still, the half-discharge potential value exhibits the same dependence of $-125 \mathrm{mV} / \mathrm{pH}$ unit (Figure 4C), confirming an identical reductive dissolution mechanism, whether there is or not $\mathrm{Mn}^{2+}$ in the electrolyte.

\subsubsection{Evidencing local pH changes in unbuffered electrolytes.}

To examine the effect of a $\mathrm{pH}$ gradient on the $\mathrm{MnO}_{2}$ discharge, we investigated unbuffered electrolytes containing solely a weak Brønsted acid at a fixed concentration of $0.36 \mathrm{M}$ (Figure 4B). The galvanostatic discharge curve obtained in an unbuffered acetic acid solution ( $\mathrm{p} K_{\mathrm{a}}=4.76, \mathrm{pH}$ adjusted to 2.95$)$ shows an upshift of the discharge plateau by $0.21 \mathrm{~V}$ compared to the acetate buffer at $\mathrm{pH}$ 5.0. An identical potential upshift $(0.2 \mathrm{~V})$ is also observed between the unbuffered $\mathrm{NH}_{4} \mathrm{Cl}$ electrolyte $\left(\mathrm{p} K_{\mathrm{a}}=9.25, \mathrm{pH}\right.$ adjusted to 5.0) and the ammonium buffer at $\mathrm{pH}$ 9.1. In this latter case, the galvanostatic discharge shows, at the beginning, a large voltage drop before to reach a plateau centered on $0.2 \mathrm{~V}$. These effects are clearly the consequence of a drastic local $\mathrm{pH}$ increase, resulting from the combined effect of the strong local consumption of protons required for the dissolution of $\mathrm{MnO}_{2}\left(4 \mathrm{H}^{+}\right.$per $\mathrm{Mn}$ reduced, see Equation 1) and of initial electrolyte conditions that are far from being buffered. The potential finally tends to stabilize because the weak acid $\mathrm{AH}$ is locally converted to its conjugated base $\mathrm{A}^{-}$, therefore reaching locally a dynamic equilibrium with the continuous flux 
of $\mathrm{AH} / \mathrm{A}^{-}$arriving/leaving by diffusion. Consequently, the local $\mathrm{pH}$ and so the discharge potential rapidly reach a steady state value governed by the $\mathrm{p} K_{\mathrm{a}}$ of the weak acid and the local relative concentrations of $\mathrm{AH}$ and $\mathrm{A}^{-}$. These results suggest that the $\mathrm{MnO}_{2}$ electrode acts as a $\mathrm{pH}$ electrode capable of continuously sense the local $\mathrm{pH}$ change during the charge/discharge steps. Using the linear $\mathrm{pH}$-dependence of the half-discharge potential established in buffered solution (Figure 4C), we can extrapolate the local $\mathrm{pH}$ generated at the $\mathrm{MnO}_{2}$ film in unbuffered electrolytes (represented by the horizontal dotted lines in Figure 4, linking the half-discharge potentials in $4 \mathrm{~B}$ to the linear plots in $4 \mathrm{C}$ ). Typically, we infer a local $\mathrm{pH}$ of $\sim 7.5$ for the $\mathrm{NH}_{4} \mathrm{Cl}$ electrolyte, whereas it is $\sim 3.1$ for the acetic acid electrolyte. This local $\Delta \mathrm{pH}$ between the two electrolytes is in line with their $\Delta \mathrm{p} K_{\mathrm{a}}$ of 4.5 .

Finally, the results obtained in buffered and unbuffered electrolytes demonstrate that the $\mathrm{p} K_{\mathrm{a}}$ of the weak acid directly affects the thermodynamic of the discharging process, but without significantly impacting the efficiency of the process. It also provides a better understanding of why water, with its high $\mathrm{p} K_{\mathrm{a}}$ of 14 , does not contribute to the reductive dissolution of $\mathrm{MnO}_{2}$ in the potential window we investigated here.

\subsubsection{Effect of multivalent metal ions $\left(\mathrm{Zn}^{2+}, \mathrm{Mn}^{2+}\right)$.}

Recently, the best performances of mild aqueous $\mathrm{Zn} / \mathrm{MnO}_{2}$ batteries were obtained in unbuffered electrolytes containing a mixture of 1-2 $\mathrm{M} \mathrm{ZnSO}_{4}$ and $0.1-0.3 \mathrm{M} \mathrm{MnSO}_{4}{ }^{10-25}$ Hence, we were interested in examining the $\mathrm{MnO}_{2}$ film discharge in aqueous electrolytes containing these multivalent cations. This interest was also motivated by our recent work demonstrating that hydrated multivalent metal cations can act as an effective source of protons to compensate the negative charge generated during the reduction of an insertion metal oxide such as $\mathrm{TiO}_{2}$ (and not, as frequently reported, to compensate the negative charge by insertion of the multivalent cation into the metal oxide). ${ }^{[38]}$

The first discharge of a $\mathrm{MnO}_{2}$ film in an aqueous solution of $0.36 \mathrm{M} \mathrm{ZnCl}_{2}$ (adjusted to $\mathrm{pH}$ 5.0) is shown in Figure 4B. The discharge curve, although less horizontal than in 
unbuffered $\mathrm{NH}_{4} \mathrm{Cl}$ or acetic acid electrolytes, show a significant discharge capacity (> 200 $\mathrm{mA} \cdot \mathrm{h} \cdot \mathrm{g}^{-1}$ ), similar to those reported in the literature. ${ }^{[11,31]}$ This significant capacity, much higher than in $1 \mathrm{M} \mathrm{KCl}$, clearly supports a faradaic mechanism where $\mathrm{MnO}_{2}$ is electrochemically reduced. Many groups attributed this discharging process to $\mathrm{Zn}$-ion insertion in $\mathrm{MnO}_{2},{ }^{[11,17,18,22,31]}$ but without considering that dissolution of multivalent metal ions in aqueous solutions leads to aquo metal ion complexes sometime characterized by a significant weak Brønsted acidity. ${ }^{[66]}$ Hence, they can act as proton donors, exactly as we have just shown above with the unbuffered acetic acid or $\mathrm{NH}_{4} \mathrm{Cl}$ electrolytes. The hexaaquo complexes $\left[\mathrm{Zn}\left(\mathrm{H}_{2} \mathrm{O}\right)_{6}\right]^{2+}$ and $\left[\mathrm{Mn}\left(\mathrm{H}_{2} \mathrm{O}\right)_{6}\right]^{2+}$ are characterized by $\mathrm{p} K_{\mathrm{a}}$ of 9.0 and $10.6,{ }^{[66]}$ respectively. The first one is close to the $\mathrm{p} K_{\mathrm{a}}$ of $\mathrm{NH}_{4}{ }^{+}\left(\mathrm{p} K_{\mathrm{a}}=9.25\right)$. Therefore, during $\mathrm{MnO}_{2}$ reduction the local $\mathrm{pH}$ change due to the consumption of protons supplied by $\left[\mathrm{Zn}\left(\mathrm{H}_{2} \mathrm{O}\right)_{6}\right]^{2+}$ should be analogous to that observed in the unbuffered $\mathrm{NH}_{4} \mathrm{Cl}$ electrolyte, with the consequence to produce discharge curves in the same potential window. This is effectively what we observe in Figure 4, from which we can estimate a local $\mathrm{pH}$ of 7.0 at half-discharge in the $\mathrm{ZnCl}_{2}$ electrolyte, which is close to the $\mathrm{pH}$ value of $\sim 7.5$ determined in $\mathrm{NH}_{4} \mathrm{Cl}$. Still, the gravimetric capacity in $\mathrm{ZnCl}_{2}$ remains much lower than in $\mathrm{NH}_{4} \mathrm{Cl}$ at the same concentration. This can be interpreted by the precipitation of zinc hydroxides due to the local $\mathrm{pH}$ increase, as previously suggested. ${ }^{[10,33,34,67]}$ The formation of zinc hydroxides over the $\mathrm{MnO}_{2}$ film may also contribute to the steeper discharge curve in $\mathrm{ZnCl}_{2}$ than in $\mathrm{NH}_{4} \mathrm{Cl}$. Still, a large fraction of $\mathrm{MnO}_{2}$ is dissolved, as attested by the significant and continuous absorbance decrease upon cycling in $\mathrm{ZnCl}_{2}$ (Figure S4). This observation agrees with previous studies reporting on an important capacity fading of $\mathrm{MnO}_{2}$ in $\mathrm{Zn}^{2+}$-based aqueous electrolytes (and $\mathrm{Mn}^{2+}$ free)..$^{[10,26,34,35]}$

The galvanostatic discharge of $\mathrm{MnO}_{2}$ was also performed in $0.36 \mathrm{M} \mathrm{MnCl}_{2}$ (adjusted to $\mathrm{pH}$ 5.0) to compare with $0.36 \mathrm{M} \mathrm{ZnCl}_{2}$. The two discharge curves exhibit very similar 
shapes and gravimetric capacities, the only difference being the downshift by $\sim 0.21 \mathrm{~V}$ for the $\mathrm{Mn}^{2+}$ - versus $\mathrm{Zn}^{2+}$-based electrolyte (Figure 4B). This is again fully consistent with Equation 2 (or its equivalent eq. S3) which predicts a potential shift of $\sim 0.2 \mathrm{~V}$ from the $\Delta \mathrm{p} K_{\mathrm{a}}$ of 1.6 we have between the two hexaaquo metal ion complexes.

To definitely rule out the presumed insertion of divalent metal ions in $\mathrm{MnO}_{2}$, the galvanostatic discharge was also investigated in $0.36 \mathrm{M} \mathrm{CaCl}_{2}$ (adjusted to $\mathrm{pH} 5.0$ ). Contrary to $\mathrm{Zn}^{2+}$ and $\mathrm{Mn}^{2+}$, the aquo $\mathrm{Ca}^{2+}$ ion is a very weak acid $\left(\mathrm{p} K_{\mathrm{a}} \sim 12.7\right),{ }^{[66]}$ nearly as weak as water. As expected, the corresponding discharge curve (Figure 4B) overlay with the one recorded in $1 \mathrm{M} \mathrm{KCl}$, demonstrating an almost purely capacitive behavior and so no faradaic discharge either by charge compensation with $\mathrm{Ca}^{2+}$ insertion or by proton-coupled reductive dissolution.

Overall, these observations demonstrate that the same mechanism of proton-coupled electron transfer is at work in both $\mathrm{Mn}^{2+}$ - and $\mathrm{Zn}^{2+}$-based electrolytes, wherein the corresponding weak acid hexaaquo metal ion complexes, $\left[\mathrm{M}\left(\mathrm{H}_{2} \mathrm{O}\right)_{6}\right]^{2+}$, act as proton donors to assist the reductive dissolution of $\mathrm{MnO}_{2}$ into $\mathrm{Mn}^{2+}$, according to the following global reaction:

$$
\mathrm{MnO}_{2(\mathrm{~s})}+4\left[\mathrm{M}\left(\mathrm{H}_{2} \mathrm{O}\right)_{6}\right]^{2+}+2 \mathrm{e}^{-} \leftrightarrows \mathrm{Mn}^{2+}{ }_{(\mathrm{aq})}+4\left[\mathrm{M}\left(\mathrm{H}_{2} \mathrm{O}\right)_{5} \mathrm{OH}\right]^{+}+2 \mathrm{H}_{2} \mathrm{O}
$$

In the specific case of the $\mathrm{Mn}^{2+}$-based electrolyte, it is interesting to note that the weak acid $\left[\mathrm{Mn}\left(\mathrm{H}_{2} \mathrm{O}\right)_{6}\right]^{2+}$ induces its own formation during the conversion of $\mathrm{MnO}_{2}$ into $\mathrm{Mn}^{2+}$.

\subsection{Reversible cycling in presence of $\mathrm{Mn}^{2+}$ in buffered aqueous solutions at pH 5}

The next question we addressed is the cyclability of a $\mathrm{MnO}_{2}$ electrode in the $1 \mathrm{M}$ acetate buffer ( $\mathrm{pH}$ 5.0) containing $\mathrm{Mn}^{2+}$. For such purpose, we carried out a series of spectroelectrochemical experiments similar to those reported in Figure 2, but with a systematic addition of $0.1 \mathrm{M} \mathrm{MnCl}_{2}$ (Figure 5). The CVs (Figure 5A) show a drastically different behavior than in the absence of $\mathrm{MnCl}_{2}$, displaying here a reversible faradaic process. 
At the beginning of the first forward reduction scan (started at $0.95 \mathrm{~V}$ ), an anodic current is generated due to the electrochemical oxidation of $\mathrm{Mn}^{2+}$ that leads to $\mathrm{MnO}_{2}$ deposition over the film already present on the ITO surface. The film growth is corroborated by the concomitant electrode absorbance increase. As the potential is progressively decreased, two reduction peaks are observed at 0.52 and $0.45 \mathrm{~V}$ with a parallel sudden decrease of the electrode absorbance, signing the $\mathrm{MnO}_{2}$ dissolution. In the reverse scan, the current intensity as well as the absorbance stays very low until the potential reaches the onset oxidation peak of $\mathrm{Mn}^{2+}$ into $\mathrm{MnO}_{2}$, at $E>0.7 \mathrm{~V}$. In the subsequent $\mathrm{CV}$ scans, the two reduction peaks remain present but broader and shifted to more negative potentials, while during the reoxidative scan the oxidation peak of $\mathrm{Mn}^{2+}$ continue to be observed without significant change except of a slight increase in intensity. The absorbance traces in Figure 5A also evidence the growth of $\mathrm{MnO}_{2}$ on ITO. These results clearly support a reversible process based on the electrodissolution and electrodeposition of manganese.

The reversible conversion is also well observed in the galvanostatic experiments of Figure 5B. As expected, the first discharge curve leads to the reductive dissolution of $\sim 80 \%$ of the as-electrodeposited $\mathrm{MnO}_{2}$ film (see the absorbance trace in Figure 5B). During the subsequent galvanostatic charge $\left(Q_{\text {charge }}\right.$ of $\left.25 \mathrm{mC} \cdot \mathrm{cm}^{-2}\right)$, the potential is nearly instantaneously switched to a maximal value of $\sim 0.8 \mathrm{~V}$ followed then by a rapid stabilization to a remarkably constant potential value of $0.61 \mathrm{~V}$. This potential fluctuation at the beginning of the charge is reminiscent of the nucleation and growth mechanism occurring at the early stage of $\mathrm{MnO}_{2}$ electrodeposition. ${ }^{[68]}$ The stable potential reached after a few tens of seconds is close to the equilibrium potential calculated using eq. 3 (represented by the horizontal dotted line in Figure 5B) and also to the one recorded under OCP. This observation suggests that the two-electron transfer reaction required for the electrodeposition of $\mathrm{MnO}_{2}$ is fast, and thus mainly governed by thermodynamics under the selected experimental conditions. It also implies that the process occurs without significant gradients of $\left[\mathrm{Mn}^{2+}\right]$ or $\mathrm{pH}$ at the electrode 
interface. This assertion was confirmed by the galvanostatic charges recorded either in the same buffer without $\mathrm{MnCl}_{2}$ or in an unbuffered electrolyte made of only $\mathrm{MnCl}_{2}$, both adjusted to $\mathrm{pH} 5$ (see Figure S5). In both cases, the charging potential is not stable because of the strong gradients of $\mathrm{pH}$ or $\left[\mathrm{Mn}^{2+}\right]$ that develop at the electrode interface (see discussion in the SI). These results are particularly interesting because they underline the benefit of using buffered electrolytes to both stabilize the charge and discharge potentials (which is advantageous for the development of stable voltage batteries) and control the voltage hysteresis between the two.

Upon continuously cycling the $\mathrm{MnO}_{2}$ electrode in the $1 \mathrm{M}$ acetate buffer containing $0.1 \mathrm{M} \mathrm{Mn}^{2+}$ (Figure 5B), the discharging capacity rapidly rises up to reach, after a few cycles, a steady state that remains quite stable without apparent fading over 50 cycles (reaching a coulombic efficiency close to $100 \%$, see Figure 5C). This steady-state is also corroborated by the highly stable absorbance oscillation between charged and discharged states (Figure 5B). All these results finally demonstrate that a constant quantity of $\mathrm{MnO}_{2}$ is reversibly dissolved and deposited at each cycle (Figure 5C) over an almost constant fraction of less reactive $\mathrm{MnO}_{2}$.

The shape of the subsequent potentiometric discharges also differs significantly from the first one, showing two plateaus, a first at $0.56 \mathrm{~V}$ close to the equilibrium potential, which accounts for $30 \%$ of the discharge process, and a second more spread out, at $\sim 0.18 \mathrm{~V}$, accounting for the remaining $70 \%$. The switch between a single plateau during the first discharge to two plateaus during the subsequent discharges is reminiscent of other studies (Table S2), but so far not understood. ${ }^{[10,11,29,35]}$ The dynamics of this two plateaus discharge process was further investigated by performing a GITT experiment at a cycled $\mathrm{MnO}_{2}$ electrode (Figure S6). The OCP reached at the end of the relaxation time is almost constant over the entire experiment $(0.54 \pm 0.02 \mathrm{~V})$ and here again close to the equilibrium potential calculated with eq. 3, consistent with a conversion mechanism. 
At the end of the 10 discharging/charging cycles, the final mass of $\mathrm{MnO}_{2}$ was 25.3 $\mu \mathrm{g} \cdot \mathrm{cm}^{-2}$ (determined by ICP), a value which is practically doubled as compared to the initial mass, confirming the accumulation of a poorly electroactive fraction of $\mathrm{MnO}_{2}$ during the first cycles. On the basis of this final mass, a reversible gravimetric discharge capacity of 274 $\mathrm{mA} \cdot \mathrm{h} \cdot \mathrm{g}^{-1}$ is obtained. This is typically in line with the capacities reported for a wide range of $\mathrm{MnO}_{2}$ electrodes in mild aqueous electrolytes (see Table S2), ${ }^{[27]}$ which led several groups to assume a one-electron reduction of $\mathrm{MnO}_{2}$ into $\mathrm{Mn}^{\mathrm{III}}$-oxide species. ${ }^{[1,17,18,21,22]}$ Here, we clearly show that this modest capacity, close to the half-capacity of $\mathrm{MnO}_{2}$, results rather from an incomplete utilization of the material itself.

The final mass of $\mathrm{MnO}_{2}$ was also determined (by ICP titration) for a set of electrodes that were subjected to different galvanostatic cycling procedures (see Table S3 where all the experimental details are gathered). The total $\mathrm{MnO}_{2}$ mass variation $\left(\Delta m_{\mathrm{MnO}_{2}}=m_{\mathrm{MnO}_{2}}^{f}-m_{\mathrm{MnO}_{2}}^{i}\right)$, reported in Figure 6 linearly correlates with the total charge $a_{\text {rotal }}$ cumulated during each cycling experiment. From the linear regression fit, an average gravimetric capacity of $540 \pm$ $20 \mathrm{~mA} \cdot \mathrm{h} \cdot \mathrm{g}^{-1}$ was determined. Since this value reflects both the overall electrodeposited and electrodissolved fractions of $\mathrm{MnO}_{2}$, it demonstrates that the oxidative and reductive processes involve the same average number of $\sim 1.75 \mathrm{e}^{-}$per Mn center over the entire range of cycling conditions tested.

Finally, from the data reported in Table S3, we notice that increasing the charging time at a moderate rate leads to an increase of the gravimetric capacities (see for instance samples 3 and 5). This is especially obvious for the electrode we have subjected to a gradual increase of the charging time (Figure 6). After a few cycles, the discharge capacity as well as the absorbance change increase proportionally with the charging time (and thus with $Q_{\text {charge }}$ ), with a $C E$ that also tends towards $100 \%$. In the meantime, the absorbance of the discharged electrode reaches a constant value, indicating the formation of a stable fraction of unreactive 
$\mathrm{MnO}_{2}$, independent of the charging time. Consequently, the ratio of electroactive versus poorly electroactive $\mathrm{MnO}_{2}$ is significantly enhanced, and so the gravimetric capacity. Assuming a $100 \% C E$ for the last charging step of $1000 \mathrm{~s}$, a remarkably high gravimetric capacity of $450 \mathrm{~mA} \cdot \mathrm{h} \cdot \mathrm{g}^{-1}$ can be estimated based on the final mass of $\mathrm{MnO}_{2}$ (see Table $\mathrm{S} 3$, sample 5), finally demonstrating a very good utilization of the $\mathrm{MnO}_{2}$ film (as high as 84 wt. \%). At the high rate of $1.6 \mathrm{~A} \cdot \mathrm{g}^{-1}$, this gravimetric capacity outperforms all those previously reported at $\mathrm{MnO}_{2}$ electrodes in mild aqueous electrolytes (Table S2).

\section{Conclusion}

The overall results presented here shed new light on the reactivity of $\mathrm{MnO}_{2}$ in mild aqueous media, leading us to propose a revisited interpretation of its charge storage mechanism. The major outcome is the demonstration of a reversible conversion mechanism associated to the faradaic electrodeposition-electrodissolution of the manganese species. This mechanism is conceptually analogous to that reported in strongly acidic $^{[8,9]}$ or basic electrolytes, ${ }^{[7]}$ the main difference being the nature of the proton donor/proton acceptor couple. In acidic electrolytes, the proton donor is naturally $\mathrm{H}_{3} \mathrm{O}^{+}$, while the proton acceptor is water. In strongly alkaline media, the proton source is the solvent $\mathrm{H}_{2} \mathrm{O}$. In such corrosive electrolytes, the high concentration of $\mathrm{H}_{3} \mathrm{O}^{+}$or $\mathrm{OH}^{-}$maintains the $\mathrm{pH}$ at a relatively stable value, and so the charge/discharge voltages. As we show here, in mild aqueous electrolytes, the reversible reductive dissolution of $\mathrm{MnO}_{2}$ into $\mathrm{Mn}^{2+}$ can also be achieved, however only in the presence of a sufficiently high concentration of a weak Brønsted acid. In addition, due to the conversion principle, it is necessary to add a reasonably high concentration of $\mathrm{Mn}^{2+}$ in the electrolyte to ensure an efficient back electrodeposition of $\mathrm{MnO}_{2}$. The benefit of adding the conjugate base in the electrolyte is to neutralize the protons released during the recharging process, and thereby to stabilize its potential. We can thus conclude that buffered electrolytes loaded with $\mathrm{Mn}^{2+}$ are best suited to achieve a high gravimetric capacity and stable voltage at 
$\mathrm{MnO}_{2}$ electrodes. In the present case, the maximal theoretical capacity of $\mathrm{MnO}_{2}$ is limited to $540 \mathrm{~mA} \cdot \mathrm{h} \cdot \mathrm{g}^{-1}$ because the conversion process involves an effective number of $\sim 1.75 \mathrm{e}^{-}$per Mn. To make the best use of this capacity, it is essential to find experimental conditions that avoid or minimize the accumulation of unreactive $\mathrm{MnO}_{2}$ during cycling. The present results show that this objective can be partly achieved by optimizing the charging time.

Another important finding of the present study relies on the unsuspected role played by multivalent metal ions such as $\mathrm{Zn}^{2+}$ and $\mathrm{Mn}^{2+}$, commonly present in the aqueous electrolytes of rechargeable $\mathrm{Zn} / \mathrm{MnO}_{2}$ batteries. The weak acidity of their hydrated forms must be definitely considered as an effective source of protons to assist the conversion of $\mathrm{MnO}_{2}$ into $\mathrm{Mn}^{2+}$. This is in the same vein as what we have previously shown at $\mathrm{TiO}_{2}$ electrodes, ${ }^{[38]}$ and it is a general concept that extends most likely far beyond metal oxides.

\section{Supporting Information}

Experimental section, Characterization of the as-electrodeposited $\mathrm{MnO}_{2}$ films; Thermodynamic analysis of the $\mathrm{MnO}_{2} / \mathrm{Mn}^{2+}$ reaction; Figures $\mathrm{S} 1$ to S6; Tables $\mathrm{S} 1$ to $\mathrm{S} 3$.

\section{Acknowledgements}

The authors thank Gurvan Le Faucheur (U.F.R. de Chimie, Université de Paris) for ICP analysis, Philippe Decorse and Sarra Gam Derouich (ITODYS, CNRS, Université de Paris) for XPS measurements and SEM imaging, respectively. We also gratefully acknowledge financial support from the National Research Agency (ANR AqReBat project). 


\section{References}

[1] C. M. Julien, A. Mauger, Nanomaterials 2017, 7, 396.

[2] Y. Tang, S. Zheng, Y. Xu, X. Xiao, H. Xue, H. Pang, Energy Storage Mater. 2018, 12, 284.

[3] A. Biswal, B. Chandra Tripathy, K. Sanjay, T. Subbaiah, M. Minakshi, $R S C A d v$. 2015, $5,58255$.

[4] J. Shin, J. K. Seo, R. Yaylian, A. Huang, Y. S. Meng, Int. Mater. Rev. 2019, 1.

[5] W. J. Wruck, B. Reichman, K. R. Bullock, W. -H. Kao, J. Electrochem. Soc. 1991, 138, 3560.

[6] M. Winter, R. J. Brodd, Chem. Rev. 2004, 104, 4245.

[7] G. Yadav, J. W. Gallaway, D. E. Turney, M. Nyce, J. Huang, X. G.Wei, S. Banerjee, Nat. Commun. 2017, 8, 14424.

[8] W. Chen, G. Li, A. Pei, Y. Li, L. Liao, H. Wang, J. Wan, Z. Liang, G. Chen, H. Zhang, J. Wang, Y. Cui, Nat. Energy 2018, 3, 428.

[9] D. Chao, W. Zhou, C. Ye, Q. Zhang, Y. Chen, L. Gu, K. Davey, S. Z. Qiao, Angew. Chemie - Int. Ed. 2019, 7823.

[10] H. Pan, Y. Shao, P. Yan, Y. Cheng, K. S. Han, Z. Nie, C. Wang, J. Yang, X. Li, P. Bhattacharya, K. T. Mueller, J. Liu, Nat. Energy 2016, 1, 16039.

[11] N. Zhang, F. Cheng, J. Liu, L. Wang, X. Long, X. Liu, F. Li, J. Chen, Nat. Commun. 2017, 8, 405.

[12] B. Wu, G. Zhang, M. Yan, T. Xiong, P. He, L. He, X. Xu, L. Mai, Small 2018, 14, 1.

[13] T. Xiong, Z. G. Yu, H. Wu, Y. Du, Q. Xie, J. Chen, Y.-W. W. Zhang, S. J. Pennycook, W. S. V. Lee, J. Xue, Adv. Energy Mater. 2019, 9, 1803815.

[14] G. Fang, C. Zhu, M. Chen, J. Zhou, B. Tang, X. Cao, X. Zheng, A. Pan, S. Liang, Adv. Funct. Mater. 2019, 29, 1808375.

[15] M. Li, Q. He, Z. Li, Q. Li, Y. Zhang, J. Meng, X. Liu, S. Li, B. Wu, L. Chen, Z. Liu, W. 
Luo, C. Han, L. Mai, Adv. Energy Mater. 2019, 9, 1901469.

[16] D. Wang, L. Wang, G. Liang, H. Li, Z. Liu, Z. Tang, J. Liang, C. Zhi, ACS Nano 2019, $13,10643$.

[17] Q. Zhao, X. Chen, Z. Wang, L. Yang, R. Qin, J. Yang, Y. Song, S. Ding, M. Weng, W. Huang, J. Liu, W. Zhao, G. Qian, K. Yang, Y. Cui, H. Chen, F. Pan, Small 2019, 15, 1904545.

[18] W. Qiu, Y. Li, A. You, Z. Zhang, G. Li, X. Lu, Y. Tong, J. Mater. Chem. A 2017, 5, 14838.

[19] X. Wu, Y. Xiang, Q. Peng, X. Wu, Y. Li, F. Tang, R. Song, Z. Liu, Z. He, X. Wu, J. Mater. Chem. A 2017, 5, 17990.

[20] Y. Zeng, X. Zhang, Y. Meng, M. Yu, J. Yi, Y. Wu, X. Lu, Y. Tong, Adv. Mater. 2017, $29,1$.

[21] Q. Huang, W. Wei, B. Han, L. Xiao, L. Chen, Y. Deng, D. Zhang, S. Zhao, D. G. Ivey, J. Mater. Chem. A 2018, 6, 5733.

[22] J. Huang, X. Dong, Y. Wang, Y. Xia, M. Hou, Y. Liu, Z. Wang, Nat. Commun. 2018, 9, 1.

[23] Y. Fu, Q. Wei, G. Zhang, X. Wang, J. Zhang, Y. Hu, D. Wang, L. Zuin, T. Zhou, Y. Wu, S. Sun, Adv. Energy Mater. 2018, 8, 1801445.

[24] H. Li, Z. Liu, G. Liang, Y. Huang, Y. Huang, M. Zhu, Z. Pei, Q. Xue, Z. Tang, Y. Wang, B. Li, C. Zhi, ACS Nano 2018, 12, 3140.

[25] M. Chamoun, W. R. Brant, C. W. Tai, G. Karlsson, D. Noréus, Energy Storage Mater. 2018, 15,351 .

[26] S. H. Kim, S. M. Oh, J. Power Sources 1998, 72, 150.

[27] G. Fang, J. Zhou, A. Pan, S. Liang, ACS Energy Lett. 2018, 3, 2480.

[28] C. Xu, B. Li, H. Du, F. Kang, Angew. Chemie - Int. Ed. 2012, 51, 933.

[29] M. H. Alfaruqi, V. Mathew, J. Gim, S. Kim, J. Song, J. P. Baboo, S. H. Choi, J. Kim, 
Chem. Mater. 2015, 27, 3609.

[30] K. W. Nam, H. Kim, J. H. Choi, J. W. Choi, Energy Environ. Sci. 2019, 12, 1999.

[31] W. Sun, F. Wang, S. Hou, C. Yang, X. Fan, Z. Ma, T. Gao, F. Han, R. Hu, M. Zhu, C. Wang, J. Am. Chem. Soc. 2017, 139, 9775.

[32] Y. Li, S. Wang, J. R. Salvador, J. Wu, B. Liu, W. Yang, J. Yang, W. Zhang, J. Liu, J. Yang, Chem. Mater. 2019, 31, 62036.

[33] P. Oberholzer, E. Tervoort, A. Bouzid, A. Pasquarello, D. Kundu, ACS Appl. Mater. Interfaces 2019, 11, 674 .

[34] B. Lee, H. R. Seo, H. R. Lee, C. S. Yoon, J. H. Kim, K. Y. Chung, B. W. Cho, S. H. Oh, ChemSusChem 2016, 9, 2948.

[35] S. Islam, M. H. Alfaruqi, V. Mathew, J. Song, S. Kim, S. Kim, J. Jo, J. P. Baboo, D. T. Pham, D. Y. Putro, Y. K. Sun, J. Kim, J. Mater. Chem. A 2017, 5, 23299.

[36] $\mathrm{MnSO}_{4}$ and $\mathrm{ZnSO}_{4}$ have similar high solubilities of 4 and $3.6 \mathrm{M}$, respectively, in pure water at $25^{\circ} \mathrm{C}$, which means that electrolytes containing 1-2 $\mathrm{M} \mathrm{ZnSO}_{4}+0.1-0.3 \mathrm{M}$ $\mathrm{MnSO}_{4}$ (such as those typically used aqueous $\mathrm{Zn} / \mathrm{MnO}_{2}$ batteries) are far from saturation.

[37] Y.-S. Kim, S. Kriegel, K. D. Harris, C. Costentin, B. Limoges, V. Balland, J. Phys. Chem. C 2017, 121, 10325.

[38] Y.-S. Kim, K. D. Harris, B. Limoges, V. Balland, Chem. Sci. 2019, 10, 8752.

[39] C. Costentin, J.-M. Saveant, Chem. Sci. 2019, 22, 5656.

[40] P. K. Nayak, S. Devaraj, N. Munichandraiah, Electrochem. Solid-State Lett. 2010, 13, 2010.

[41] S. L. Kuo, N. L. Wu, J. Electrochem. Soc. 2006, 153, 1317.

[42] S. Pang, M. A. Anderson, T. W. Chapman, J. Electrochem. Soc. 2000, 147, 444.

[43] W. Wei, X. Cui, W. Chen, D. G. Ivey, Chem. Soc. Rev. 2011, 40, 1697.

[44] M. Toupin, T. Brousse, D. Bélanger, Chem. Mater. 2004, 16, 3184. 
[45] C. A. Castro Ruiz, D. Bélanger, D. Rochefort, J. Phys. Chem. C 2013, 117, 20397.

[46] J. N. Broughton, M. J. Brett, Electrochim. Acta 2005, 50, 4814.

[47] M. J. Young, M. Neuber, A. C. Cavanagh, H. Sun, C. B. Musgrave, S. M. George, J. Electrochem. Soc. 2015, 162, A2753.

[48] W. Yan, J. Y. Kim, W. Xing, K. C. Donavan, T. Ayvazian, R. M. Penner, Chem. Mater. 2012, 24, 2382.

[49] K. W. Nam, M. G. Kim, K. B. Kim, J. Phys. Chem. C 2007, 111, 749.

[50] M. Toupin, T. Brousse, D. Bélanger, Chem. Mater. 2002, 14, 3946.

[51] H. Y. Lee, J. B. Goodenough, J. Solid State Chem. 1999, 144, 220.

[52] Q. Qu, P. Zhang, B. Wang, Y. Chen, S. Tian, Y. Wu, R. Holze, J. Phys. Chem. C 2009, $113,14020$.

[53] W. Yan, T. Ayvazian, J. Kim, Y. Liu, K. C. Donavan, W. Xing, Y. Yang, J. C. Hemminger, R. M. Penner, ACS Nano 2011, 5, 8275.

[54] C. Costentin, J.-M. Savéant, ACS Appl. Energy Mater. 2019, 2, 4981.

[55] G. Boschloo, D. Fitzmaurice, J. Phys. Chem. B 1999, 103, 2228.

[56] G. Garcia, R. Buonsanti, E. L. Runnerstrom, R. J. Mendelsberg, A. Llordes, A. Anders, T. J. Richardson, D. J. Milliron, Nano Lett. 2011, 11, 4415.

[57] G. Boschloo, D. Fitzmaurice, J. Phys. Chem. B 1999, 103, 7860.

[58] B. A. Pinaud, Z. Chen, D. N. Abram, T. F. Jaramillo, J. Phys. Chem. C 2011, 115, 11830.

[59] A. J. Bard, R. Parsons, J. Jordan, Eds. , Standard Potentials in Aqueous Solution, CRC Press, 1985.

[60] D. L. Parkhurst, in Chem. Model. Aqueous Syst. II, American Chemical Society, 1990, pp. $3-30$.

[61] D. B. Broughton, R. L. Wentworth, M. E. Laing, J. Am. Chem. Soc. 1947, 69, 744.

[62] M. Nakayama, A. Sato, R. Yamaguchi, Electroanalysis 2013, 25, 2283. 
[63] A. S. Ryabova, A. Bonnefont, P. Zagrebin, T. Poux, R. Paria Sena, J. Hadermann, A. M. Abakumov, G. Kéranguéven, S. Y. Istomin, E. V. Antipov, G. A. Tsirlina, E. R. Savinova, ChemElectroChem 2016, 3, 1667.

[64] C. Amatore, S. Szunerits, L. Thouin, J. S. Warkocz, J. Electroanal. Chem. 2001, 500, 62.

[65] $\mathrm{Mn}^{2+}$ remains soluble at $\mathrm{pH} 9.1$ as long as $\mathrm{a}_{\mathrm{Mn} 2+}<1.25 \times 10^{-3}$.

[66] S. J. Hawkes, J. Chem. Educ. 1996, 73, 516.

[67] In a $0.36 \mathrm{M} \mathrm{Zn}^{2+}$ solution, precipitation of $\mathrm{Zn}(\mathrm{OH})_{2}$ is expected to occur at $\mathrm{pH}>6.0$ (taking into account an activity of 0.105 for $\mathrm{Zn}^{2+}$ and a solubility product constant of $\mathrm{K}_{\mathrm{s}}$ $\left.=3 \times 10^{-17}\right)$.

[68] A. Milchev, I. Montenegro, J. Electroanal. Chem. 1992, 333, 93. 

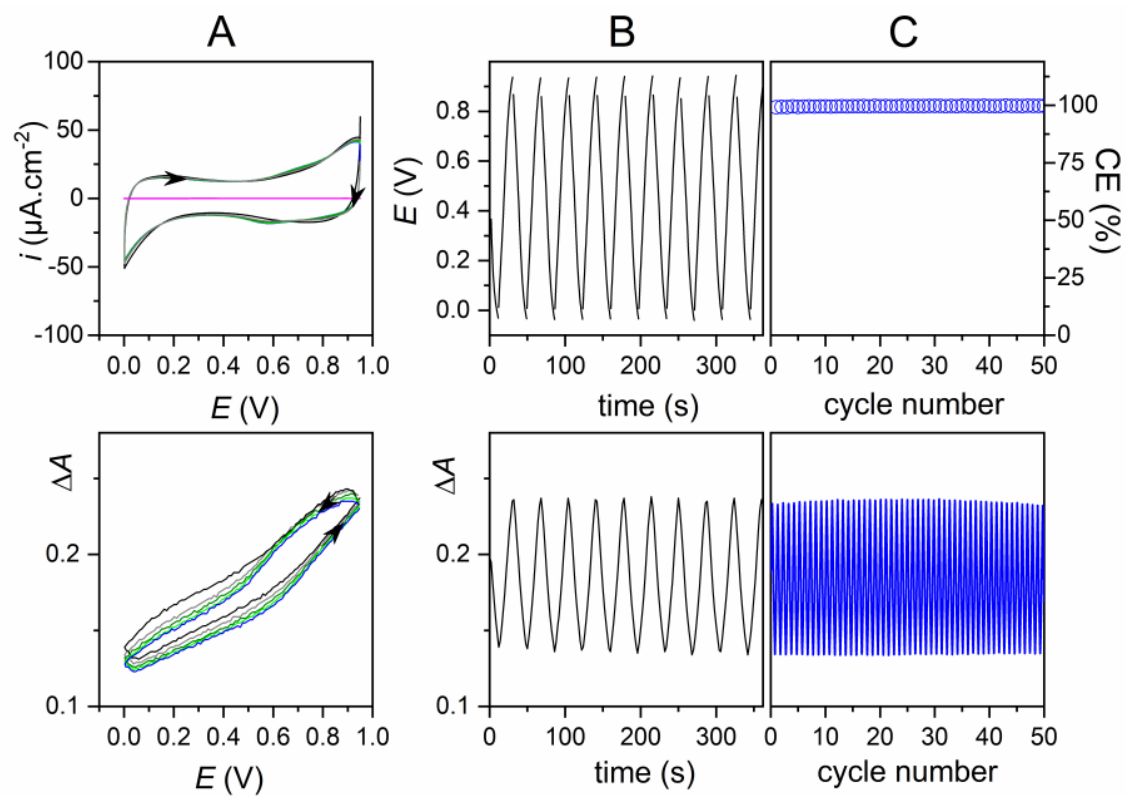

Figure 1. (A) Five successive (top) CVs and (bottom) CVAs (obtained by subtracting the $\mathrm{UV}$-vis absorbance recorded at $500 \mathrm{~nm}$ to that recorded at $700 \mathrm{~nm}$, i.e. $\left.\Delta A==A_{500}-A_{700}\right)$ concomitantly monitored at an as-electrodeposited semi-transparent $\mathrm{MnO}_{2}$ thin-film ITO electrode $\left(m_{\mathrm{MnO}_{2}}^{i}=11.4 \mu \mathrm{g} \cdot \mathrm{cm}^{-2}\right)$ in $1 \mathrm{M} \mathrm{KCl}$ (adjusted to $\mathrm{pH} 5$ ). The pink curve is the background $\mathrm{CV}$ recorded at a bare ITO electrode. Scan rate: $5 \mathrm{mV} \cdot \mathrm{s}^{-1}$. (B) Continuous galvanostatic discharging/charging curves recorded at a $\mathrm{MnO}_{2}$ thin-film ITO electrode $\left(m_{\mathrm{MnO}_{2}}^{i}\right.$ $=10.8 \mu \mathrm{g} \cdot \mathrm{cm}^{-2}$ ) in $1 \mathrm{M} \mathrm{KCl}$ (adjusted to $\mathrm{pH}$ 5). The potentiometric (top) and absorptometric (bottom) traces were recorded simultaneously. The charging/discharging rate was 0.15 $\mathrm{mA} \cdot \mathrm{cm}^{-2}\left(14 \mathrm{~A} \cdot \mathrm{g}^{-1}\right) .(\mathrm{C})$ (top) Coulombic efficiency recovered from the 50 galvanostatic cycles applied as in $\mathrm{B}$ at a $\mathrm{MnO}_{2}$-coated ITO electrode and (bottom) the corresponding absorptometric trace. 

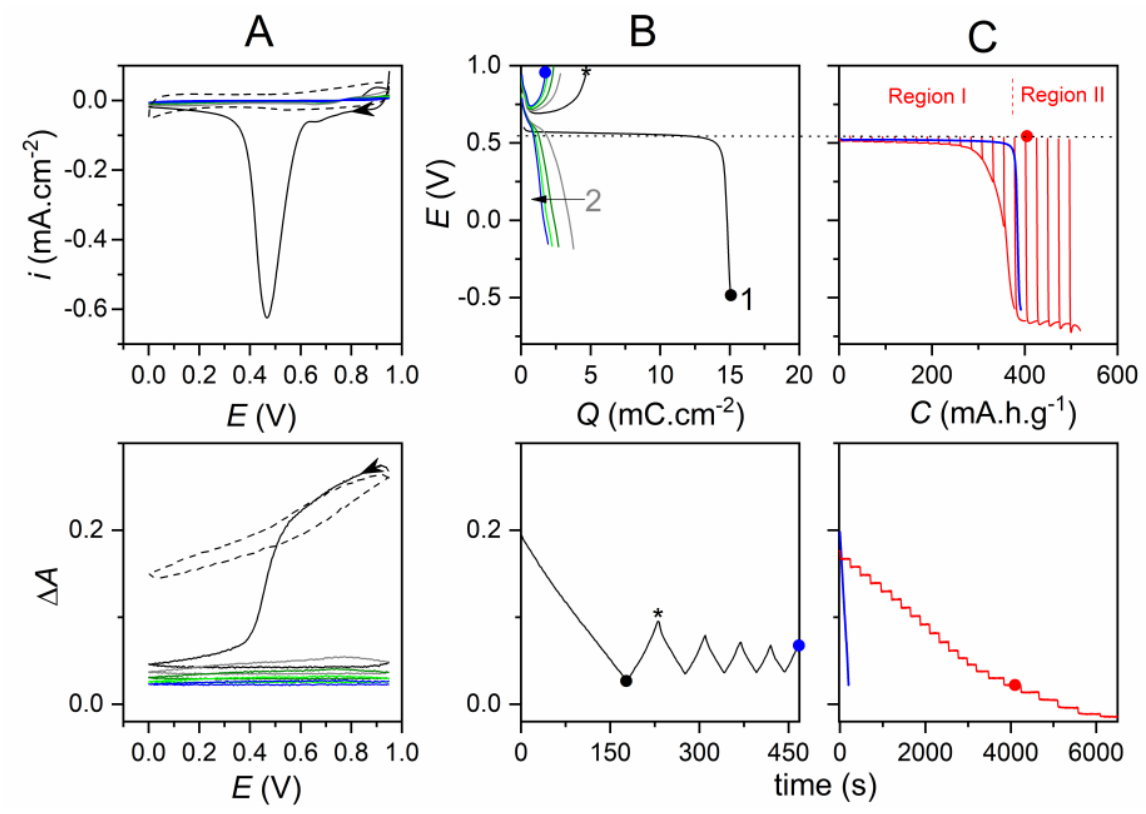

Figure 2. (A) Five successive (top) CVs and (bottom) CVAs concomitantly monitored (scan rate: $\left.5 \mathrm{mV} \cdot \mathrm{s}^{-1}\right)$ at an as-electrodeposited $\mathrm{MnO}_{2}$ thin-film ITO electrode $\left(m_{\mathrm{MnO}_{2}}^{i}=10.7 \mu \mathrm{g} \cdot \mathrm{cm}^{-2}\right)$ in a $1 \mathrm{M}$ acetate aqueous buffer $(\mathrm{pH}$ 5.0). For sake of comparison, the first $\mathrm{CV}$ and CVA (dashed lines) scanned in an unbuffered $1 \mathrm{M} \mathrm{KCl}$ aqueous electrolyte (pH 5.0) are shown. (B) Galvanostatic discharging/charging curves (5 cycles, rate: $0.17 \mathrm{~mA} \cdot \mathrm{cm}^{-2}$ ) concomitantly recorded by (top) potentiometry and (bottom) absorptometry at a $\mathrm{MnO}_{2}$ thin-film ITO electrode $\left(m_{\mathrm{MnO}_{2}}^{i}=10.3 \mu \mathrm{g} \cdot \mathrm{cm}^{-2}\right)$ in a $1 \mathrm{M}$ acetate buffer (pH 5.0). (C) First galvanostatic discharge curves obtained under (blue) continuous or (red) intermittent titration (rates: 0.08 $\left.\mathrm{mA} \cdot \mathrm{cm}^{-2}\right)$ at $\mathrm{MnO}_{2}$ thin-film ITO electrodes $\left(m_{\mathrm{MnO}_{2}}^{i}=10.8 \pm 1.2 \mu \mathrm{g} \cdot \mathrm{cm}^{-2}\right)$ in a $1 \mathrm{M}$ acetate buffer ( $\mathrm{pH}$ 5.0) containing $0.1 \mathrm{M} \mathrm{MnCl}_{2}$. The potentiometric (top) and absorptometric (bottom) traces were recorded simultaneously. For the intermittent titration, a discharge pulse of $10 \mathrm{~s}$ followed by open circuit potential measurement until dE/dt $<10 \mu \mathrm{V} \cdot \mathrm{s}^{-1}$ was repetitively applied. The horizontal dotted line crossing the top figures B and C corresponds to the theoretical equilibrium potential defined by Equation 2. 


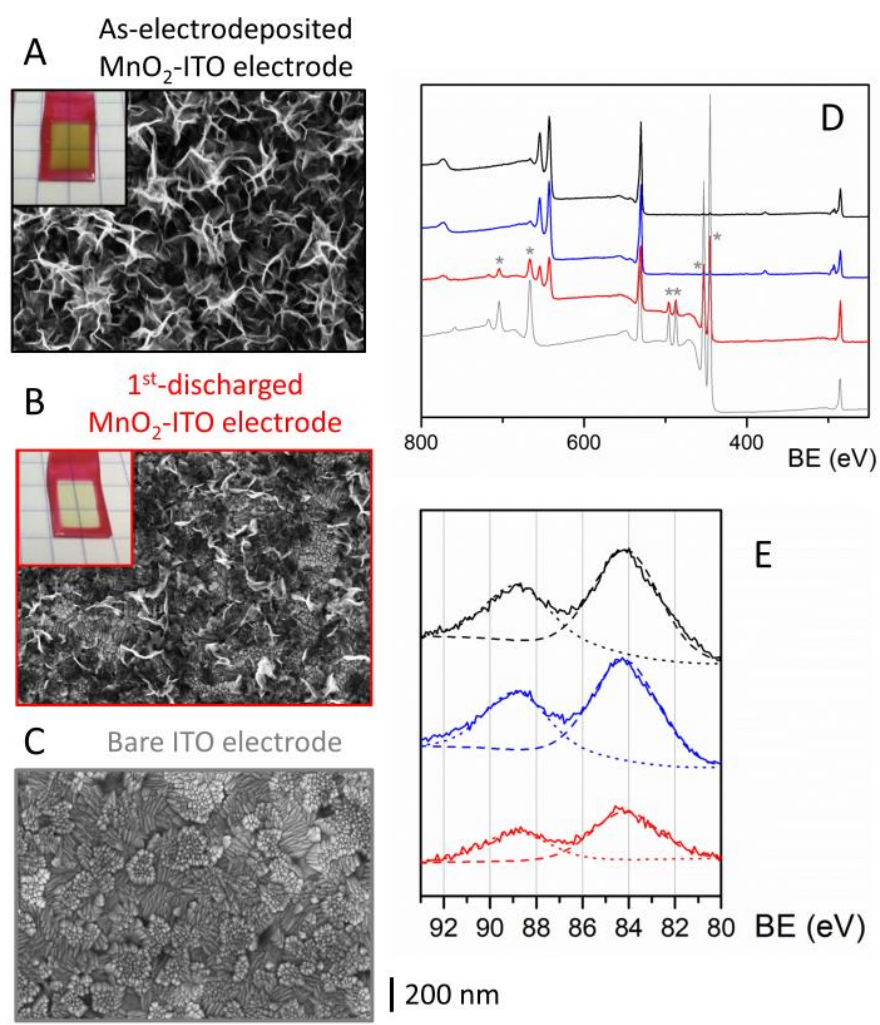

Figure 3. (Left) SEM images recorded at (A) an as-electrodeposited $\mathrm{MnO}_{2}$ thin-film ITO electrode, (B) a $\mathrm{MnO}_{2}$ thin-film ITO electrode after a first discharge in a $1 \mathrm{M}$ acetate buffer (pH 5.0) containing 0.1 $\mathrm{M} \mathrm{MnCl}_{2}$, and (C) a bare ITO electrode. (Right) (D) Survey XPS spectra and (E) high resolution Mn(3s) XPS spectra determined for the electrodes shown in (black) A, (red) B, and (grey) C. The XPS spectra in blue are those obtained for a $\mathrm{MnO}_{2}$ thinfilm ITO electrode discharged once in a $1 \mathrm{M} \mathrm{KCl}$ electrolyte ( $\mathrm{pH} 5.0)$. 


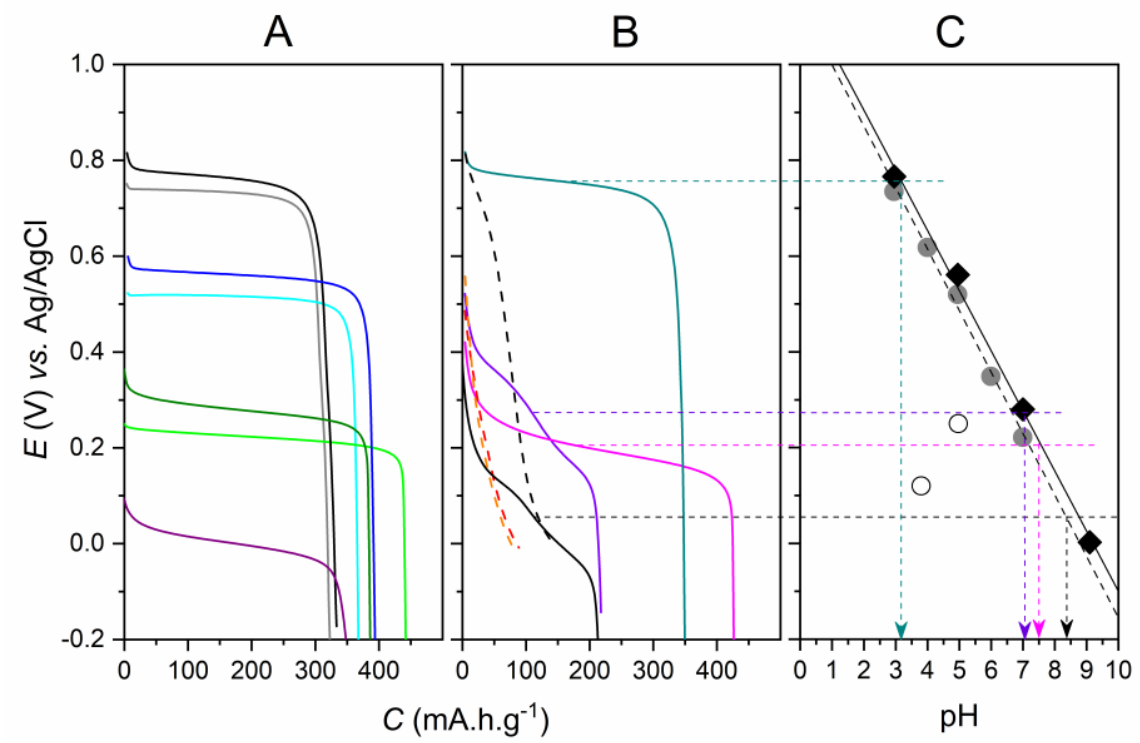

Figure 4. First galvanostatic discharges (rate: $0.088 \pm 0.005 \mathrm{~mA} \cdot \mathrm{cm}^{-2}$ ) recorded at aselectrodeposited $\mathrm{MnO}_{2}$ thin-film electrodes $\left(m_{\mathrm{MnO}_{2}}^{i}=11.4 \pm 0.7 \mu \mathrm{g} \cdot \mathrm{cm}^{-2}\right)$ in $($ A) buffered an (B) unbuffered aqueous electrolytes. The color code in A is as follows: $0.9 \mathrm{M}$ chloroacetate buffer (pH 2.95) with (black) or without (grey) $0.1 \mathrm{M} \mathrm{MnCl}_{2} ; 1.0 \mathrm{M}$ acetate buffer (pH 5.0) with (blue) and without (cyan) $0.1 \mathrm{M} \mathrm{MnCl}_{2} ; 0.45 \mathrm{M}$ HEPES buffer ( $\mathrm{pH}$ 7.0) with (olive) and without (green) $0.1 \mathrm{M} \mathrm{MnCl}_{2}$; (prune) $0.66 \mathrm{M}$ ammonium buffer ( $\mathrm{pH} 9.1$ ) without $\mathrm{MnCl}_{2}$. The color code in $\mathrm{B}$ is as follow: (dark cyan) $0.36 \mathrm{M}$ acetic acid and (dashed black) $1 \mathrm{M} \mathrm{KCl}$ aqueous electrolytes adjusted both to $\mathrm{pH} 2.95$; (magenta) $0.36 \mathrm{M} \mathrm{NH}_{4} \mathrm{Cl}$, (violet) $0.36 \mathrm{M}$ $\mathrm{ZnCl}_{2}$, (black) $0.36 \mathrm{M} \mathrm{MnCl}_{2}$, (dashed orange) $0.36 \mathrm{M} \mathrm{CaCl}_{2}$ and (dashed red) $1 \mathrm{M} \mathrm{KCl}$ aqueous electrolytes adjusted all to $\mathrm{pH}$ 5.0. (C) Half-discharge potential plotted as a function of the $\mathrm{pH}$ of buffered electrolytes, and in the $(\bullet)$ absence or $(\bigcirc)$ presence of $0.1 \mathrm{M} \mathrm{MnCl}_{2}$. The dashed horizontal lines show how to determine the local $\mathrm{pH}$ using a transfer to graph $\mathrm{C}$ (see text for details). The $\bigcirc$ symbols refer to the half-discharge potential values recovered from refs ${ }^{[11,31]}$ (recalculated vs. $\mathrm{Ag} / \mathrm{AgCl}$ ) obtained in aqueous electrolytes containing a mixture of 2-3 $\mathrm{M} \mathrm{Zn}^{2+}$ and $0.1-0.2 \mathrm{M} \mathrm{Mn}^{2+}$. These values are reported on the graph as a function of the bulk $\mathrm{pH}$ of the electrolyte. 

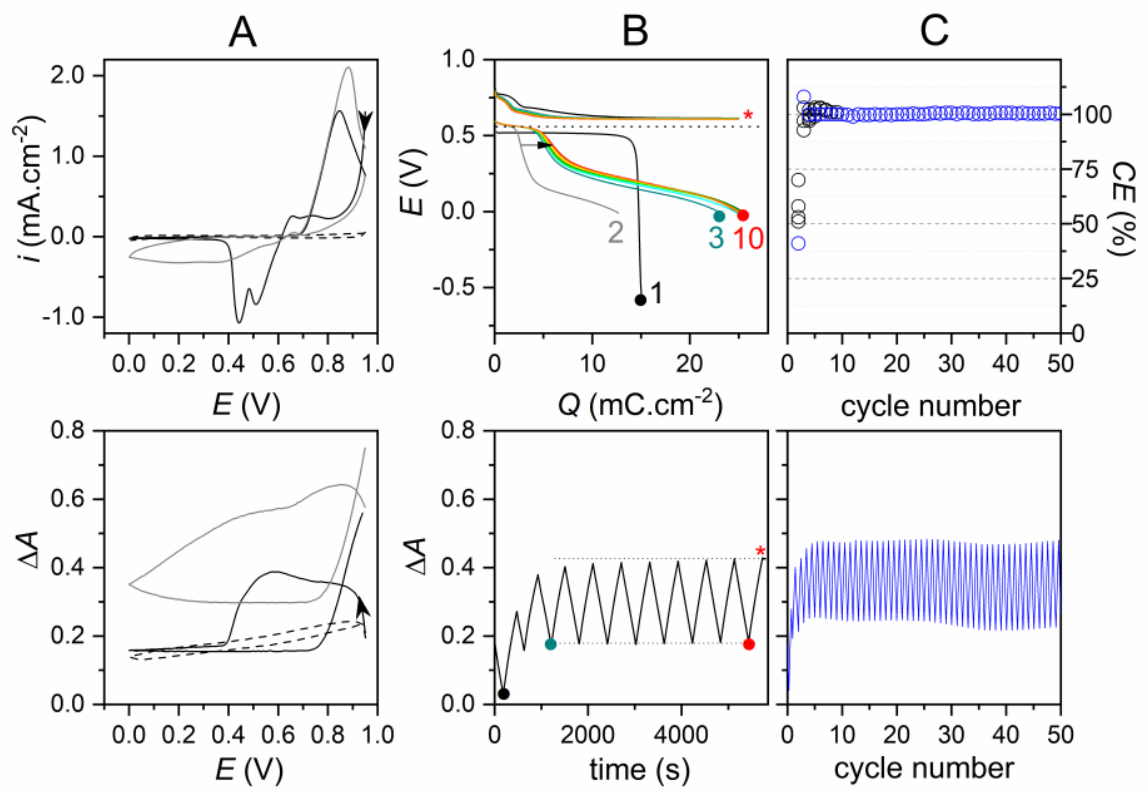

Figure 5. (A) Two consecutive CVs and CVAs concomitantly monitored (scan rate: $5 \mathrm{mV} \cdot \mathrm{s}^{-1}$ ) at a $\mathrm{MnO}_{2}$ thin-film ITO electrode $\left(m_{\mathrm{MnO}_{2}}^{i}=10.4 \mu \mathrm{g} \cdot \mathrm{cm}^{-2}\right)$ in a $1 \mathrm{M}$ acetate buffer $(\mathrm{pH} 5.0)$ containing $0.1 \mathrm{M} \mathrm{MnCl}_{2}$. For sake of comparison, the first $\mathrm{CV}$ and $\mathrm{CVA}$ (dashed lines) recorded in an unbuffered $1 \mathrm{M} \mathrm{KCl}$ aqueous electrolyte (pH 5.0) are shown. (B) Galvanostatic discharging/charging curves (10 cycles, rate: $0.083 \mathrm{~mA} \cdot \mathrm{cm}^{-2}$ ) concomitantly recorded by (top) potentiometry and (bottom) absorptometry at a $\mathrm{MnO}_{2}$ thin-film ITO electrode $\left(m_{\mathrm{MnO}_{2}}^{i}=11\right.$ $\mu \mathrm{g} \cdot \mathrm{cm}^{-2}$ ) in a $1 \mathrm{M}$ acetate buffer ( $\mathrm{pH}$ 5.0) containing $0.1 \mathrm{M} \mathrm{MnCl}_{2}$. (C) (top) Coulombic efficiency recovered from 50 galvanostatic cycles, applied as in $\mathrm{B}$ at a $\mathrm{MnO}_{2}$-coated ITO electrode and (bottom) the corresponding absorptometric trace. The black dots were recovered from the cycles in B. 

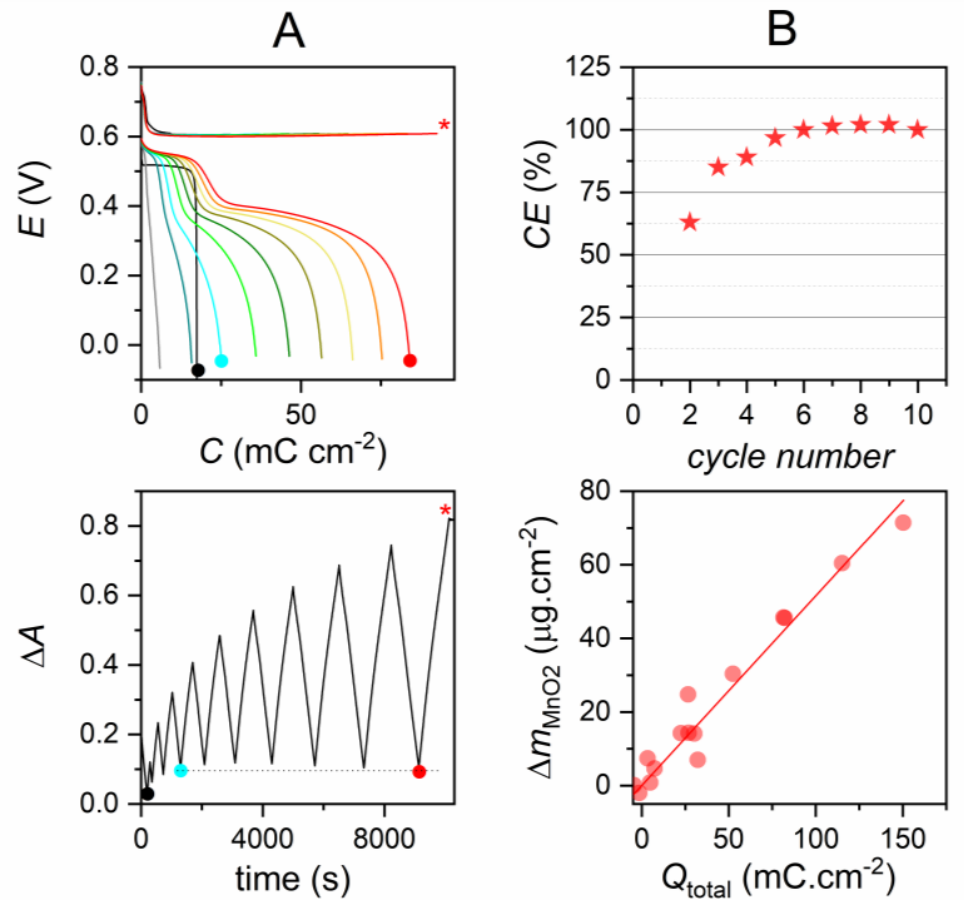

Figure 6. (A) Galvanostatic discharging/charging curves (10 cycles during which the charging time was incremented from 100 to $1000 \mathrm{~s}$ by step of $100 \mathrm{~s}$ per each cycle, rate: 0.093 $\mathrm{mA} \cdot \mathrm{cm}^{-2}$ ) concomitantly recorded by (top) potentiometry and (bottom) absorptometry at a $\mathrm{MnO}_{2}$ ITO electrode (loaded with $11 \mu \mathrm{g} \cdot \mathrm{cm}^{-2} \mathrm{MnO}_{2}$ ) in a $1 \mathrm{M}$ acetate buffer ( $\mathrm{pH}$ 5.0) with 0.1 $\mathrm{M} \mathrm{MnCl}_{2}$. The code color for the cycle number is as follow: (black) 1, (grey) 2, (dark cyan) 3, (cyan) 4, (green) 5, (olive) 6, (dark yellow) 7, (yellow) 8, (orange) 9, (red) 10. (B) (top) Coulombic efficiency extracted from the top graph in A as a function of the cycle number, and (bottom) $\Delta m_{\mathrm{MnO}_{2}}=m_{\mathrm{MnO}_{2}}^{f}-m_{\mathrm{MnO}_{2}}^{i}$ as a function of $Q_{\text {total }}$ extracted from a set of galvanostatic cycling experiments (see Table S3). The red line is the linear regression to the experimental data $\left(\right.$ slope $\left.=0.515 \pm 0.021 \mu \mathrm{g} \cdot \mathrm{cm}^{-2}, r^{2}=0.98\right)$. 
Supporting Information

\section{Accessing the two-electron charge storage capacity of $\mathrm{MnO}_{2}$ in mild aqueous electrolytes}

Mickaël Mateos, Nikolina Makivic, Yee-Seul Kim, Benoît Limoges, *Véronique Balland*
I. Experimental Section
II. Characterization of electrodeposited $\mathrm{MnO}_{2}$ thin films
III. Thermodynamic analysis of the $\mathrm{MnO}_{2} / \mathrm{Mn}^{2+}$ reaction
IV. Supplementary Figures
V. Supplementary Tables
VI. References 


\section{Experimental Section}

Chemicals. $\mathrm{Mn}(\mathrm{II})$ acetate tetrahydrate (99.99\%), $\mathrm{KNO}_{3}$ (ReagentPlus, $>$ 99.0\%), $\mathrm{HNO}_{3}$ (Suprapur, 65\%), acetic acid (Reagent plus, > 99\%), sodium acetate, chloroacetic acid, HEPES hydrate $(>99.5 \%)$, HEPES sodium salt, MES hydrate $(>99.5 \%)$, MES sodium salt, $\mathrm{NH}_{4} \mathrm{Cl}, \mathrm{KOH}, \mathrm{HCl}$ (Normapur, 37\%), $\mathrm{KCl}$ (GR for analysis), $\mathrm{NaCl}$ (GR for analysis), $\mathrm{LiCl}$ (GR for analysis), Trichloroethylene, Ethanol absolute (EMSURE), $\mathrm{ZnCl}_{2}$ were purchased from Sigma-Aldrich/Merck. $\mathrm{MnCl}_{2}$ tetrahydrate (99\%) was purchased from Alfa Aesar. Acetone (Normapur) was purchased from VWR Chemicals. ITO electrodes $(8-12 \mathrm{ohms} / \square)$ were provided by Sigma-Aldrich.

ITO electrodes cleaning. Prior to use, planar ITO electrodes were cleaned by successively sonicating them in tricholoroethylene, acetone and ethanol for 15 minutes each. After the electrodes were left to dry, a working square planar ITO area of $0.6 \pm 0.1 \mathrm{~cm}^{2}(\mathrm{~N}=$ 20) was delimited using a nail vanish.

Preparation of the $\mathrm{MnO}_{2}$-coated ITO electrodes. $\mathrm{MnO}_{2}$ thin-films on transparent ITO electrodes were obtained from electrodeposition at a controlled anodic potential in a standard three-electrode cell configuration, using a CHI900 potentiostat $(\mathrm{CH}$ Instruments), a SCE reference electrode $(+0.244 \mathrm{~V}$ vs. NHE), and a Pt-mesh counter electrode. All electrodeposition experiments were performed at ambient temperature $\left(23 \pm 2{ }^{\circ} \mathrm{C}\right)$ in quiescent solutions. During preliminary electrochemical testing, some films peeled off the ITO surface. To improve the film adhesion on the ITO substrate, the following procedure was used. A freshly cleaned and delimited ITO electrode was placed in a $10 \mathrm{~mL}$ aqueous solution containing $1 \mathrm{mM} \mathrm{Mn}\left(\mathrm{CH}_{3} \mathrm{CO}_{2}\right)_{2}$ and $1 \mathrm{M} \mathrm{KNO}_{3}(\mathrm{pH} \sim 6.5)$. It was first scanned by cyclic voltammetry $(\mathrm{CV})$ at $50 \mathrm{mV} \cdot \mathrm{s}^{-1}$ from 0 to $1 \mathrm{~V}$ (single cyclic scan), followed by potentiostatic electrodeposition at $0.9 \mathrm{~V}$ ( $v s$. SCE) for a duration ranging from 150 to $900 \mathrm{~s}$ (corresponding thus to a deposited charge ranging from 6.7 to $33.2 \mathrm{mC} \cdot \mathrm{cm}^{-2}$ ). Concomitantly with the $\mathrm{MnO}_{2}$ film growth, the color of the initially transparent electrode gradually changes from light yellow to dark brown.

After electrodeposition, the modified electrodes were soaked for a few minutes in milliQ water and left to dry at room temperature. For a typical electrodeposition time of $600 \mathrm{~s}$, the total charge density $Q$ was $21 \pm 1 \mathrm{mC} \cdot \mathrm{cm}^{-2}(\mathrm{~N}=20)$. For each electrode, the initial amount of electrodeposited $\mathrm{MnO}_{2}\left(m_{\mathrm{MnO}_{2}}^{i}\right.$ in $\left.\mu \mathrm{g} \cdot \mathrm{cm}^{-2}\right)$ was estimated from the following equation (see section II for details):

$$
m_{\mathrm{MnO}_{2}}^{i}=0.52 \times Q
$$

Further quantitative characterizations of the as-electrodeposited electrodes by UV-visible absorption spectroscopy, XPS and ICP are reported in section II below.

Aqueous electrolytes composition. Aqueous electrolytes with the following chemical composition were prepared in milliQ water. Buffered electrolytes $\left(\mathrm{p} K_{\mathrm{a}}-1<\mathrm{pH}<\mathrm{p} K_{\mathrm{a}}+1\right)$ : $(i)$ $0.9 \mathrm{M}$ chloroacetate buffer $\left(\mathrm{p} K_{\mathrm{a}}=2.87\right)$ at $\mathrm{pH} 2.95$ (prepared from a $1 \mathrm{M}$ chloroacetic acid solution adjusted to the desired $\mathrm{pH}$ with $1 \mathrm{M} \mathrm{KOH}$ ) along with $0.3 \mathrm{M} \mathrm{KCl}$ or $0.1 \mathrm{M} \mathrm{MnCl}_{2}$ (ionic strength $I=0.92 \mathrm{M})-($ ii $) 1 \mathrm{M}$ acetate buffer $\left(\mathrm{p} K_{\mathrm{a}}=4.76\right)$ at $\mathrm{pH} 5.0$ along with $0.3 \mathrm{M}$ $\mathrm{KCl}$ or $0.1 \mathrm{M} \mathrm{MnCl}_{2}(I=1.05 \mathrm{M})-\left(\right.$ iii) $0.65 \mathrm{M} \mathrm{MES} \mathrm{buffer}\left(\mathrm{p} K_{\mathrm{a}}=6.16\right)$ at $\mathrm{pH} 6.0$ along with $0.4 \mathrm{M} \mathrm{KCl}$ or $0.1 \mathrm{M} \mathrm{MnCl}_{2}(I=0.6 \mathrm{M})-(i v) 0.45 \mathrm{M}$ HEPES buffer $\left(\mathrm{p} K_{\mathrm{a}}=7.5\right)$ at $\mathrm{pH}$ 6.9 along with $0.4 \mathrm{M} \mathrm{KCl}$ or $0.1 \mathrm{M} \mathrm{MnCl}_{2}(I=0.39 \mathrm{M})-(v) 0.66 \mathrm{M}$ ammonium buffer $\left(\mathrm{p} K_{\mathrm{a}}\right.$ $=9.23)$ at $\mathrm{pH} 9.1$ along with $0.4 \mathrm{M} \mathrm{KCl}(I=0.76 \mathrm{M})$. Unbuffered electrolytes $\left(\mathrm{pH}<\mathrm{p} K_{\mathrm{a}}-1\right)$ : $(i)$ $1 \mathrm{M} \mathrm{KCl}$ adjusted to pH 3.0 or 5.0 with $1 \mathrm{M} \mathrm{HCl}(I=1 \mathrm{M})-(i i) 0.36 \mathrm{M} \mathrm{NH}_{4} \mathrm{Cl}$ adjusted to pH 5.0 with $1 \mathrm{M} \mathrm{HCl}(I=0.36 \mathrm{M})-($ iii $) 0.36 \mathrm{M} \mathrm{ZnCl}_{2}$ adjusted to $\mathrm{pH} 5.0$ with $1 \mathrm{M} \mathrm{HCl}(I=$ $1.08 \mathrm{M})$. For all electrolytes containing $0.1 \mathrm{M} \mathrm{MnCl}_{2}$, the activity coefficient of $\mathrm{Mn}^{2+}$ 
calculated from the Truesdell-Jones equation (using a and b values of $7.04 \AA$ and $0.22 \mathrm{~L} \cdot \mathrm{mol}^{-}$ ${ }^{1}$, respectively) ${ }^{\mathrm{S}[1]}$ lies within $0.36-0.40$.

Spectroelectrochemistry. Spectroelectrochemical experiments were performed in a quartz UV-visible cell modified to accommodate three electrodes. The counter electrode was a $\mathrm{Pt}$ wire and the reference electrode was a Dri-Ref $\mathrm{Ag} / \mathrm{AgCl} / \mathrm{KCl}_{\text {sat. }}$ electrode $(+0.2 \mathrm{~V} v s$. NHE, WPI instruments). Unless otherwise stated, all reported potentials are quoted to this reference electrode. The total volume of electrolyte was $1.3 \mathrm{~mL}$. UV-visible absorption spectra were recorded in transmission mode using an HR-2000+ spectrometer (Ocean Optics) controlled by the SpectraSuite software. Typical spectra were obtained by averaging 20 (for CV experiments) or 50 (for galvanostatic experiments) individual spectra recorded with an integration time of $40 \mathrm{~ms}$. For the $\mathrm{CV}$ experiments, the spectrometer was synchronized with a AUTOLAB PG-16 potentiostat controlled by the GPES software and the scan rate fixed to 5 $\mathrm{mV} \cdot \mathrm{s}^{-1}$. For the galvanostatic experiments, the electrochemical cell was controlled by an AUTOLAB GP-11 potentiostat interfaced with the NOVA 1.11 software. Intensity was fixed to 0.05 or $0.1 \mathrm{~mA}$, which once normalized to the working electrode area leads to discharge/charge rate densities of $\sim 0.08$ and $0.16 \mathrm{~mA} \cdot \mathrm{cm}^{-2}$. Galvanostatic intermittent titration experiments (GITT) were performed at $0.05 \mathrm{~mA}$ (i.e., $\sim 0.08 \mathrm{~mA} \cdot \mathrm{cm}^{-2}$ ) by applying a discharge pulse of $10 \mathrm{~s}$ followed by OCP measurement until $d E / d t<10 \mu \mathrm{V} \cdot \mathrm{s}^{-1}$.

In the $\mathrm{KCl}$ electrolyte, the apparent specific gravimetric capacitance of the $\mathrm{MnO}_{2}$ film $\left(C_{f}\right.$ in $\mathrm{F} \cdot \mathrm{g}^{-1}$ ) was assessed from the galvanostatic experiments using the following equation:

$$
C_{f}=1000 \frac{Q}{\Delta E \times m_{\mathrm{MnO}_{2}}^{i}}
$$

where $Q\left(\mathrm{mC} \cdot \mathrm{cm}^{-2}\right)$ is the total charge passed during either the charging or discharging step, $\Delta E$ the scanned potential window $(0.95 \mathrm{~V})$, and $m_{\mathrm{MnO}_{2}}^{i}\left(\mu \mathrm{g} \cdot \mathrm{cm}^{-2}\right)$ the initial electrodeposited mass of $\mathrm{MnO}_{2}$.

The coulombic efficiency $(C E)$ of the discharging/charging cycle $i$ (with $i>1$ ) was defined as:

$$
C E_{i}(\%)=\frac{t_{i, \text { discharge }}}{t_{i-1, \text { charge }}}
$$

where $t_{i, \text { discharge }}$ is the time of the discharging step $i$ and $t_{i-1, \text { charge }}$ is the time of the previous charging step $i-1$. The cumulated charge $a_{\text {total }}$ passed at the electrode during successive galvanostatic cycles was calculated from the following equation:

$$
Q_{\text {total }}=\sum_{i} Q_{i}=\sum_{i}\left(Q_{i, \text { discharge }}+Q_{i, \text { charge }}\right)=|i| \sum_{i}\left(t_{i, \text { charge }}-t_{i, \text { discharge }}\right)
$$

Film characterization. Scanning electron microscopy was performed using a Supra40 Zeiss microscope operating at $5 \mathrm{kV}$. XPS spectra were recorded using a K-Alpha+ system (ThermoFisher Scientific, East-Grinsted, UK) fitted with a micro-focused and monochromatic $\mathrm{Al} \mathrm{K} \alpha \mathrm{X}$-ray source $(1486.6 \mathrm{eV}$, spot size of $400 \mu \mathrm{m})$. The pass energy was set to 150 and 40 $\mathrm{eV}$ for the survey and the narrow high resolution regions, respectively. The spectra were calibrated against the $(\mathrm{C}-\mathrm{C} / \mathrm{C}-\mathrm{H}) \mathrm{C}(1 \mathrm{~s})$ component set at $285 \mathrm{eV}$. The chemical composition was determined by using the manufacturer sensitivity factors using the Avantage software (version 5.977). The average oxidation state (AOS) of the $\mathrm{Mn}$ centers in the electrodeposited $\mathrm{MnO}_{2}$ thin-film was estimated on the basis of the XPS $\mathrm{Mn}(3 \mathrm{~s})$ peak splitting energy $(\triangle B E)$ and using the following correlation: ${ }^{\mathrm{S} 2, \mathrm{~S} 3}$

$$
\mathrm{AOS}=8.95-1.13 \triangle B E(\mathrm{eV})
$$


The amount of $\mathrm{MnO}_{2}$ electrodeposited on ITO was analyzed by inductively coupled plasma atomic emission spectrometry (ICP-AES; Thermo Scientific iCAP 6300 ICP spectrometer) after dissolving the $\mathrm{MnO}_{2}$ film in concentrated nitric acid under ultrasonication and dilution with reagent-grade water to $6.5 \% \mathrm{v} / \mathrm{v}$ nitric acid concentration.

\section{Characterization of electrodeposited $\mathrm{MnO}_{2}$ thin films}

To get well adhesive, uniform and reproducible thin layers of $\mathrm{MnO}_{2}$ on flat ITO substrates, a specific electrodeposition procedure has been implemented (see Experimental Section I). The adhesion improvement may be explained by a better control of the $\mathrm{MnO}_{2}$ nuclei formation during the $\mathrm{CV}$ preconditioning, involving uniformly distributed grains, which act as anchor points and thus strengthen the adhesion and cohesiveness of the film. The uniformity of the deposit is attested by the homogeneity of the slight coloration of modified electrodes (from light brown/yellow to dark brown with the increase of film thickness). SEM images evidence a uniform film of sheetlike nanostructures, arranged perpendicular to the ITO surface (Figure Sa), leading to a highly nanostructured porous film. Such a morphology is typical to that previously reported for electrodeposited $\mathrm{MnO}_{2} \cdot{ }^{[\mathrm{S} 4-\mathrm{S} 13]}$ Further XRD analysis of the film did not allow for discernible diffraction peaks, confirming the amorphous state of $\mathrm{MnO}_{2}$.

The amount of $\mathrm{MnO}_{2}$ (or $\mathrm{Mn}$ ) on the ITO electrode was determined after dissolution of the film in nitric acid followed by analysis of the Mn content by ICP-AES. It can be seen in Figure $\mathrm{Sb}$ that the surface concentration of Mn centers $\left(m_{\mathrm{Mn}}\right.$ in $\left.\mu \mathrm{g} \cdot \mathrm{cm}^{-2}\right)$ scales linearly to the total charge density $Q$ (in $\mathrm{mC} \cdot \mathrm{cm}^{-2}$ ) passed during the potentiostatic deposition in a $1 \mathrm{mM}$ $\mathrm{Mn}^{2+}$ solution, leading for instance to $7.1 \pm 0.3 \mu \mathrm{g} \cdot \mathrm{cm}^{-2}$ of $\mathrm{Mn}$ (or $11.2 \pm 0.5 \mu \mathrm{g} \cdot \mathrm{cm}^{-2}$ of $\mathrm{MnO}_{2}$ ) after $600 \mathrm{~s}$ at $0.9 \mathrm{~V}$ (vs. SCE). The data were fitted with a linear regression model, giving the following equation:

$$
m_{\mathrm{Mn}}=1000 \times \frac{M_{\mathrm{Mn}}}{n F} \times Q=(0.33 \pm 0.01) \times Q
$$

where $M_{\mathrm{Mn}}$ is the atomic weight of $\mathrm{Mn}\left(55 \mathrm{~g} \cdot \mathrm{mol}^{-1}\right), F$ the Faraday constant $\left(96485 \mathrm{C} \cdot \mathrm{mol}^{-1}\right)$ and $n$ the average number of electrons passed per deposited Mn center (Equation S1 can be easily converted into a surface concentration of $\mathrm{MnO}_{2}$, i.e. $m_{\mathrm{MnO} 2}$, by taking into account the molecular weight of $\mathrm{MnO}_{2}$, which we have assumed of pure $\mathrm{MnO}_{2}$, i.e. $87 \mathrm{~g} \cdot \mathrm{mol}^{-1}$ ). Assuming that, at the deposition potential of $0.9 \mathrm{~V}$, the electrodeposition of $\mathrm{MnO}_{2}$ is achieved with $100 \%$ coulombic efficiency (which is reasonable considering that at this low potential there is no significant faradaic contribution resulting from the oxidation of water ${ }^{[\mathrm{S5}]}$ ), a $n$ value of 1.74 can thus be inferred, which is lower than the expected theoretical value of 2 associated to the oxidation of $\mathrm{Mn}^{\mathrm{II}}$ into $\mathrm{Mn}^{\mathrm{IV}}$. This nonstochiometric $n$ value indicates the presence of cation vacancies in the $\mathrm{MnO}_{2}$ structure, which can arise either from the missing of $\mathrm{Mn}^{\mathrm{IV}}$ in the lattice or the substitution of $\mathrm{Mn}^{\mathrm{IV}}$ by $\mathrm{Mn}^{\mathrm{III}} \cdot{ }^{[\mathrm{S} 14, \mathrm{~S} 15]}$ This $n$ value is similar to that previously reported for potentiostatic deposition of $\mathrm{MnO}_{2}$ under comparable ${ }^{[\mathrm{S5}]}$ or somewhat different ${ }^{[\mathrm{S} 12, \mathrm{~S} 16]}$ experimental conditions. Additionally, this value is in good agreement with the AOS of $\mathrm{Mn}$ estimated by XPS from the Mn 3s peak splitting energy $(\triangle B E) .{ }^{[\mathrm{S} 2]}$ Indeed, we obtained a $\triangle B E$ value of $4.65 \pm 0.10 \mathrm{eV}$ (see Table S1 and Figure $\mathrm{Sb}$ ), which corresponds to an AOS of 3.7 (see Experimental Section) and so justify our assumption of $100 \%$ coulombic efficiency during the electrodeposition process. Such a $\triangle B E$ value is also analogous to that previously reported for $\mathrm{MnO}_{2}$ thin films prepared by potentiostatic deposition (> $0.6 \mathrm{~V} v s$. $\mathrm{Ag} / \mathrm{AgCl})^{[\mathrm{S} 16, \mathrm{S17}]}$ and it lies within the range of the 4.6-4.7 eV reported for crystalline $\gamma$ and $\beta$ $\mathrm{MnO}_{2}$ structures. ${ }^{[\mathrm{S} 3]}$ The XPS analysis also evidences the presence of some $\mathrm{K}^{+}$cations, arising most likely from the metal oxide lattice as the electrodes were prior to analysis thoroughly 
rinsed with milliQ water to avoid any contribution from the electrolyte. According to the Ruetschi formalism ${ }^{\left[{ }^{[14]}\right.}$ the chemical formula of the electrodeposited film can thus be written as $\mathrm{Mn}^{\mathrm{IV}}{ }_{1-x-y} \mathrm{Mn}^{\mathrm{III}} \diamond_{y} \diamond_{x} \mathrm{O}_{2} \mathrm{~K}_{0.09} \mathrm{H}_{4 x+y-0.09}$, where $\diamond$ are $\mathrm{Mn}^{\text {IV }}$ vacancies. On the basis of the good concordance between the $n$ value recovered from ICP and the AOS of Mn inferred from XPS, we deduced the absence of cation vacancies in the $\mathrm{MnO}_{2}$ structure $(x=0)$, so we can conclude that the chemical formula of the as-electrodeposited film is $\mathrm{Mn}^{\mathrm{IV}}{ }_{0.72} \mathrm{Mn}^{\mathrm{III}}{ }_{0.28} \mathrm{O}_{2} \mathrm{~K}_{0.09} \mathrm{H}_{0.19}$ (Table S1). For sake of simplicity, it will still be referred as $\mathrm{MnO}_{2}$ throughout the manuscript.

The UV-visible absorption spectra of the $\mathrm{MnO}_{2}$ films, electrodeposited with different loads on ITO, were recorded under open circuit potential (OCP) (Figure Sb). As expected, higher loads yielded higher absorbance values due to the increase amount of $\mathrm{MnO}_{2}$. The absorbance difference $\left(\triangle A_{\mathrm{OCP}}\right)$, determined from the subtraction of the absorbance recorded at $\lambda=700 \mathrm{~nm}$ and $500 \mathrm{~nm}$ (to subtract the ITO and electrolyte contributions) under OCP, follows a linear relationship as a function of the amount of electrodeposited $\mathrm{MnO}_{2}\left(m_{\mathrm{MnO}_{2}}\right.$ in $\left.\mu \mathrm{g} \cdot \mathrm{cm}^{-2}\right)$ (Figure $\mathrm{Sb}$ ). From the best fit of a linear regression model to the experimental data, arising from 35 independent electrodes, the following equation was obtained $\left(r^{2}=0.92\right)$ :

$$
\Delta A_{\mathrm{OCP}}=m_{\mathrm{MnO}_{2}} \times(18.6 \pm 0.9) \times 10^{-3}-0.012
$$

A simple measurement of the UV-vis absorbance of the film under OCP can thus be used to easily and roughly estimate the surface concentration of $\mathrm{MnO}_{2}$ on the ITO surface using Equation S2.
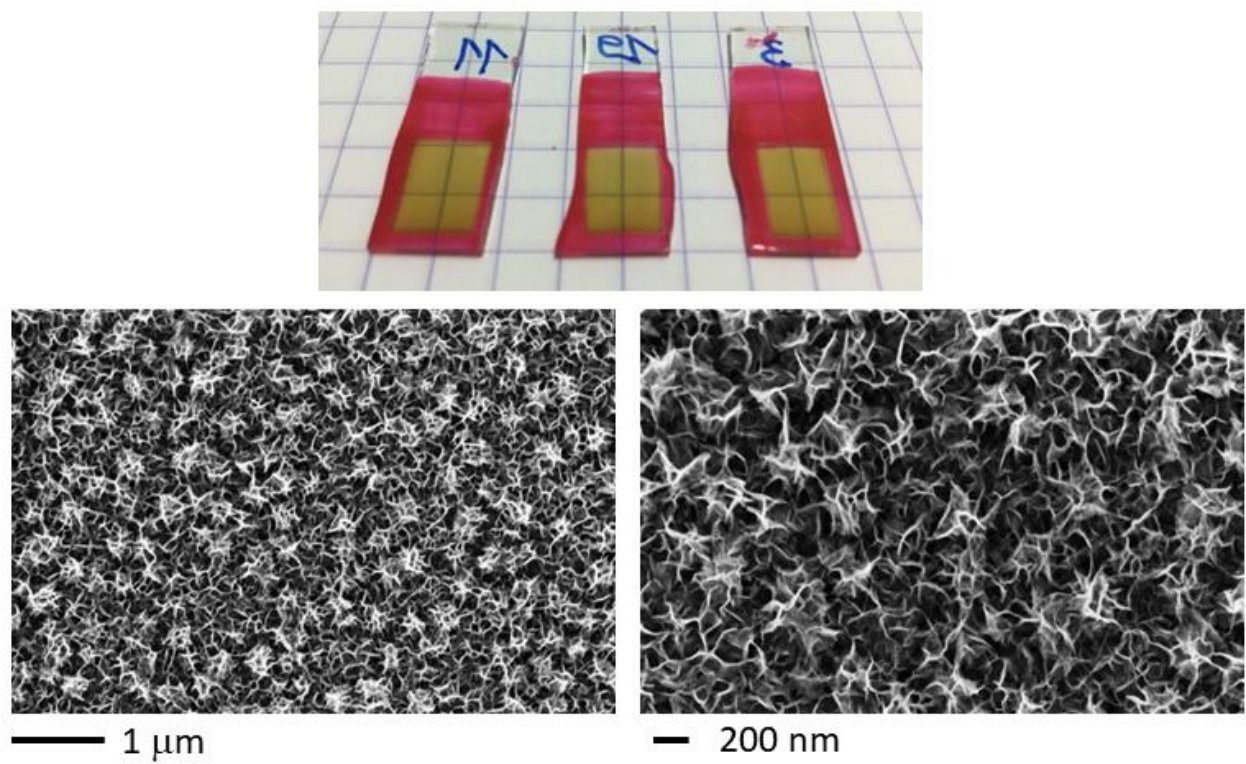

Figure Sa. (top) Macroscopic and (bottom) SEM images (top views) of as-electrodeposited $\mathrm{MnO}_{2}$ thin-films on ITO. 

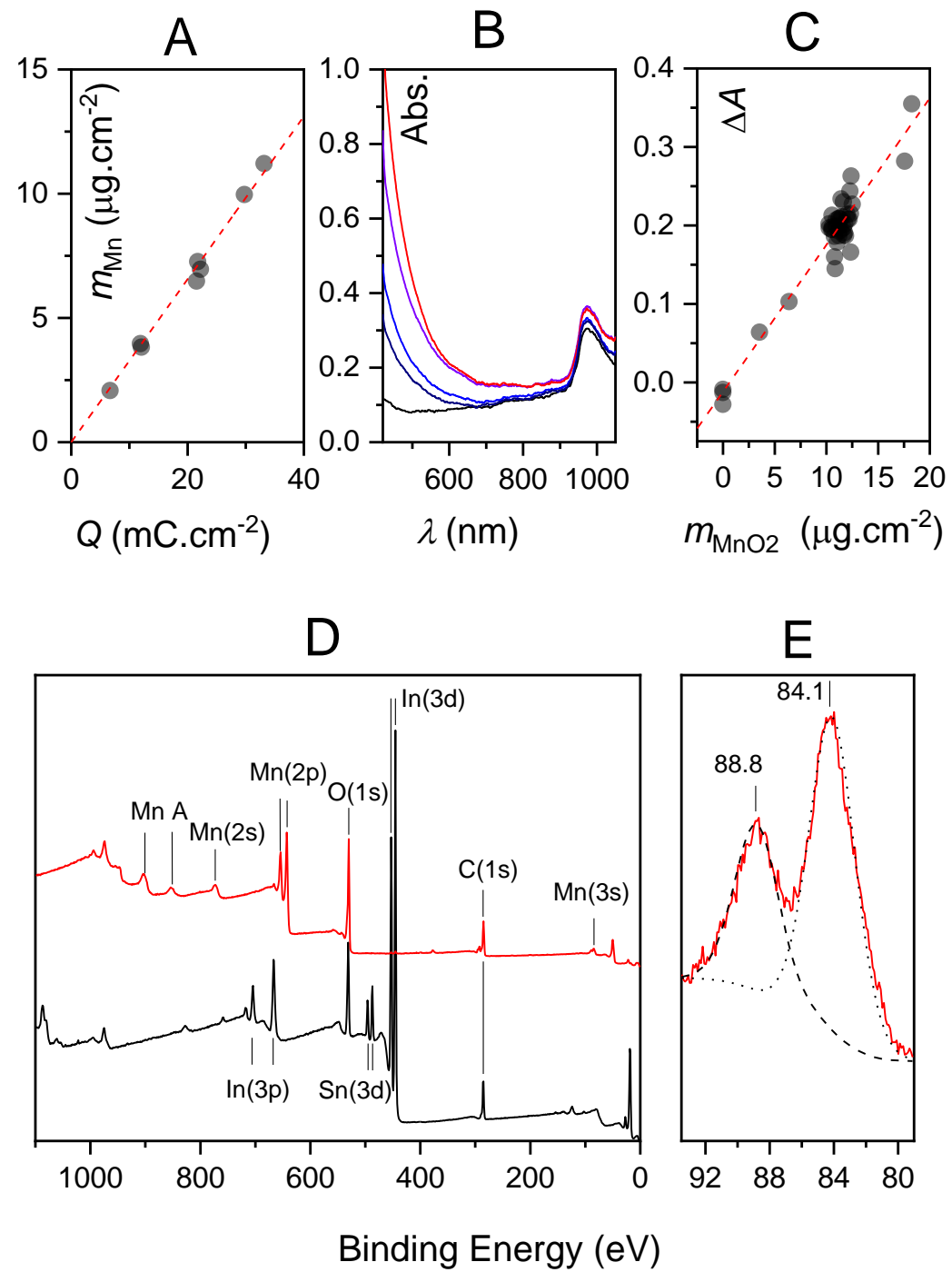

Figure Sb. Characterizations of the as-electrodeposited $\mathrm{MnO}_{2}$ thin-films on ITO. (A) Surface mass of Mn deposited on ITO, determined by ICP (see Experimental Section), as a function of the charge density passed during the potentiostatic deposition. The dashed red line corresponds the linear regression with a slope of $0.328 \pm 0.004 \mu \mathrm{g} \cdot \mathrm{mC}^{-1}\left(r^{2}=0.998\right)$. (B) UVvisible absorption spectra recorded at a bare ITO electrode (black) and at different $\mathrm{MnO}_{2}$ thinfilms ITO electrodes obtained with an increasing potentiostatic electrodeposition time of 150 $\mathrm{s}$ (navy), $300 \mathrm{~s}$ (blue), $600 \mathrm{~s}$ (purple), and $900 \mathrm{~s}$ (red). The total charge passed during the electrodeposition process was 6.7, 12.1, 21.7 and $33.2 \mathrm{mC} \cdot \mathrm{cm}^{-2}$, respectively. (C) Absorbance difference, i.e. $\Delta A=A_{500}-A_{700}$, as a function of mass of $\mathrm{MnO}_{2}$ film. The experimental data were fitted with a linear regression, leading to a slope of $(18.6 \pm 0.9) \times 10^{-3} \mathrm{~cm}^{2} \cdot \mu^{-1}$ and an intercept of $-0.012 \pm 0.012\left(r^{2}=0.92\right)$. (D) XPS Survey spectra recorded at a bare (black) and $\mathrm{MnO}_{2}$-coated ITO electrode (red, charged at $21.7 \mathrm{mC} \cdot \mathrm{cm}^{-2}$ ). (E) High resolution XPS spectra of the Mn 3s. The black curves correspond to the two fitted components $(\triangle B E=4.7 \mathrm{eV})$. 


\section{Thermodynamic analysis of the $\mathrm{MnO}_{2} / \mathrm{Mn}^{2+}$ reaction}

Let consider the following global reaction under unbuffered conditions characterized by a standard potential $E^{0}$ :

$$
\mathrm{MnO}_{2(\mathrm{~s})}+4 \mathrm{H}^{+}+2 \mathrm{e}-\leftrightarrows \mathrm{Mn}^{2+}+2 \mathrm{H}_{2} \mathrm{O} \quad E^{0}
$$

From this reaction we can thus write the Nernst equation:

$$
E=E^{0}+\frac{R T}{2 F} \ln \frac{a_{\mathrm{MnO}_{2}}\left(a_{\mathrm{H}^{+}}\right)^{4}}{a_{\mathrm{Mn}^{2+}}\left(a_{\mathrm{H}_{2} \mathrm{O}}\right)^{2}}
$$

and so

$$
E=E^{0}-\frac{R T}{2 F} \ln a_{\mathrm{Mn}^{2+}}-2 \frac{R T}{F} \mathrm{pH}
$$

which at $25^{\circ} \mathrm{C}$ leads to $E=E^{0}-0.12 \mathrm{pH}-0.03 \log a_{\mathrm{Mn}^{2+}}$

If now we consider the same reaction in the presence of a weak acid characterized by a $\mathrm{p} K_{\mathrm{a}}$, then we can write:

$$
\begin{array}{ll}
\mathrm{MnO}_{2(\mathrm{~s})}+4 \mathrm{H}^{+}+2 \mathrm{e}-\leftrightarrows \mathrm{Mn}^{2+}+2 \mathrm{H}_{2} \mathrm{O} & E^{0} \\
\mathrm{AH} \leftrightarrows \mathrm{A}^{-}+\mathrm{H}^{+} & K_{\mathrm{a}}
\end{array}
$$

$\mathrm{pH}=\mathrm{p} K_{a}-\log \left(\frac{a_{\mathrm{AH}}}{a_{\mathrm{A}^{\circ}}}\right)$

which at $25^{\circ} \mathrm{C}$ leads to $E=E^{0}-0.12 \mathrm{p} K_{a}+0.12 \log \left(\frac{a_{\mathrm{AH}}}{a_{\mathrm{A}^{-}}}\right)-0.03 \log a_{\mathrm{Mn}^{2+}}$ 


\section{Supplementary Figures}

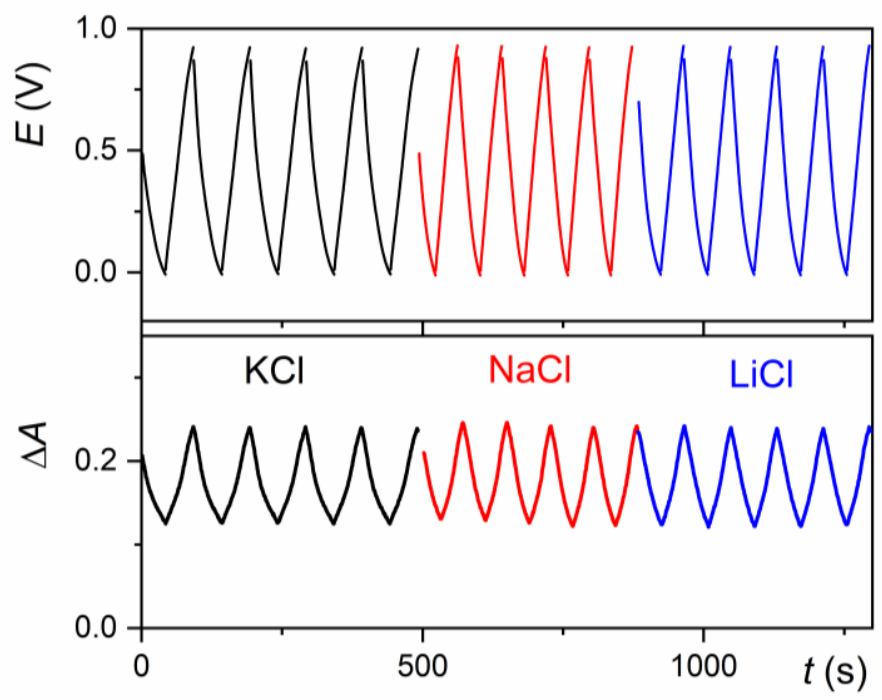

Figure S1. Galvanostatic charging/discharging curves at $0.08 \mathrm{~mA} / \mathrm{cm}^{2}$ simultaneously recorded by (top) potentiometry and (bottom) absorptiometry at an as-electrodeposited $\mathrm{MnO}_{2}$ thin-film electrode (loaded with $10.1 \mu \mathrm{g} \cdot \mathrm{cm}^{-2}$ ) successively immersed in (black) $1 \mathrm{M} \mathrm{KCl}$, (red) $1 \mathrm{M} \mathrm{NaCl}$, and (blue) $1 \mathrm{M} \mathrm{LiCl}$ aqueous electrolyte (all adjusted to $\mathrm{pH} 5$ ). The cut-off potentials were fixed to 0.95 and $0 \mathrm{~V}$.
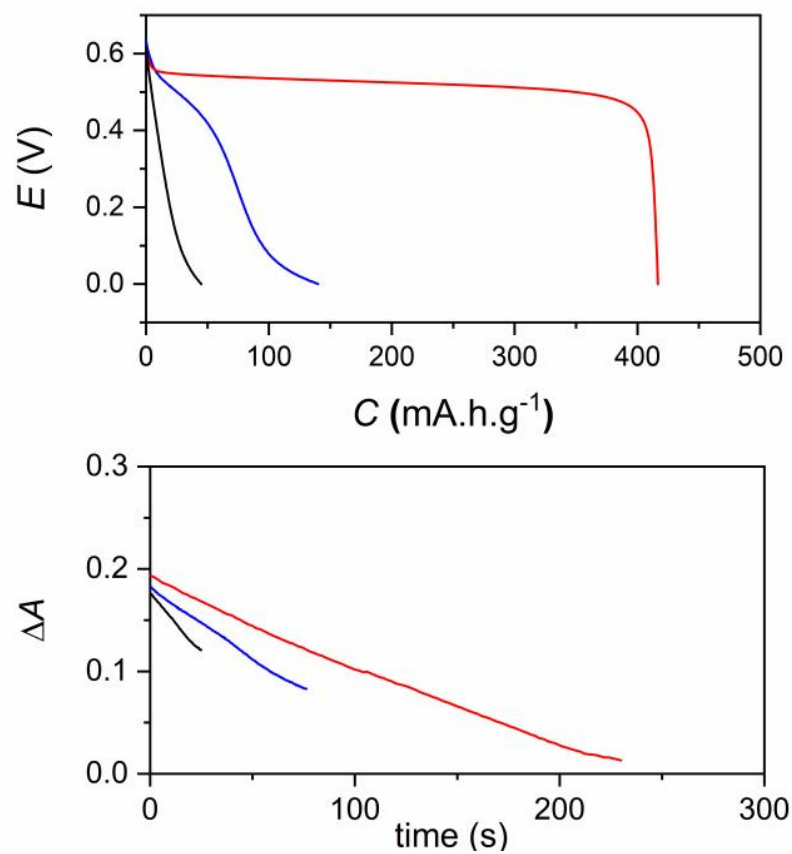

Figure S2. First galvanostatic discharges of as-electrodeposited $\mathrm{MnO}_{2}$ electrodes simultaneously recorded at $0.08 \mathrm{~mA} / \mathrm{cm}^{2}$ by (top) potentiometry and (bottom) absorptiometry in different aqueous electrolytes $(\mathrm{pH} 5.0)$ containing $1 \mathrm{M} \mathrm{KCl}$ and an increasing acetate buffer concentration of: (black) $1 \mathrm{mM}$, (blue) $10 \mathrm{mM}$ and (red) $100 \mathrm{mM}$. The cut-off potential was fixed to $0 \mathrm{~V}$. 

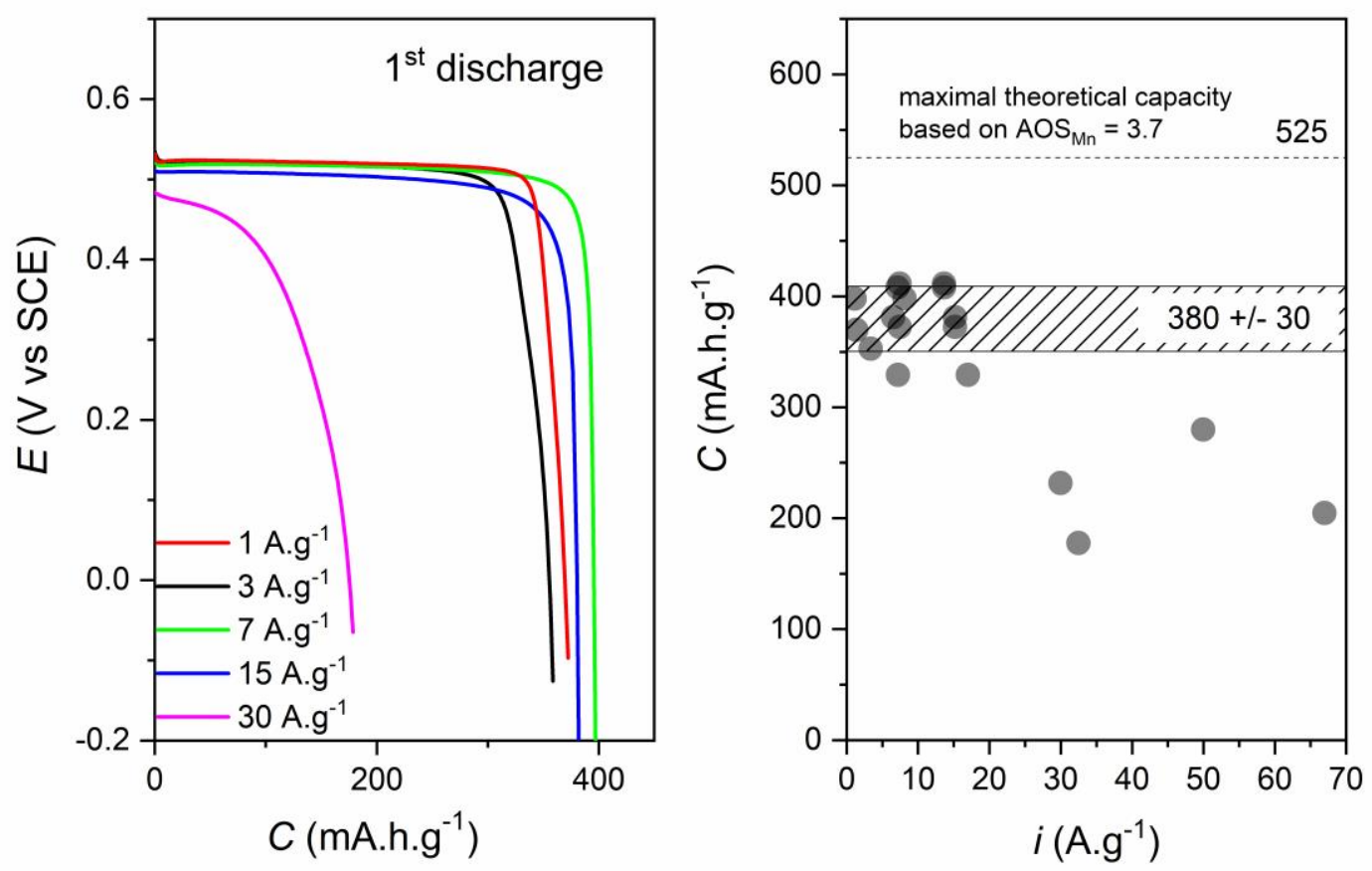

Figure S3. (Left) First galvanostatic discharges of as-electrodeposited $\mathrm{MnO}_{2}$ electrodes recorded at different rates in an acetate buffer $\left(1 \mathrm{M}, \mathrm{pH}\right.$ 5.0) containing $0.1 \mathrm{M} \mathrm{MnCl}_{2}$. (Right) First discharge gravimetric capacities determined from experiments similar to those reported on the left graph. The dashed line at $525 \mathrm{~mA} \cdot \mathrm{h} \cdot \mathrm{g}^{-1}$ is the maximal theoretical gravimetric capacity that the as-electrodeposited $\mathrm{MnO}_{2}$ film can deliver once fully reduced to $\mathrm{Mn}^{2+}$ (calculated with a number of 1.7 electron per $\mathrm{Mn}$ ). The hatched area represents the mean value of the maximal gravimetric capacity \pm its standard deviation, determined at low rates (< $20 \mathrm{~A} \cdot \mathrm{g}^{-1}$ ) with 14 independent $\mathrm{MnO}_{2}$ electrodes. 

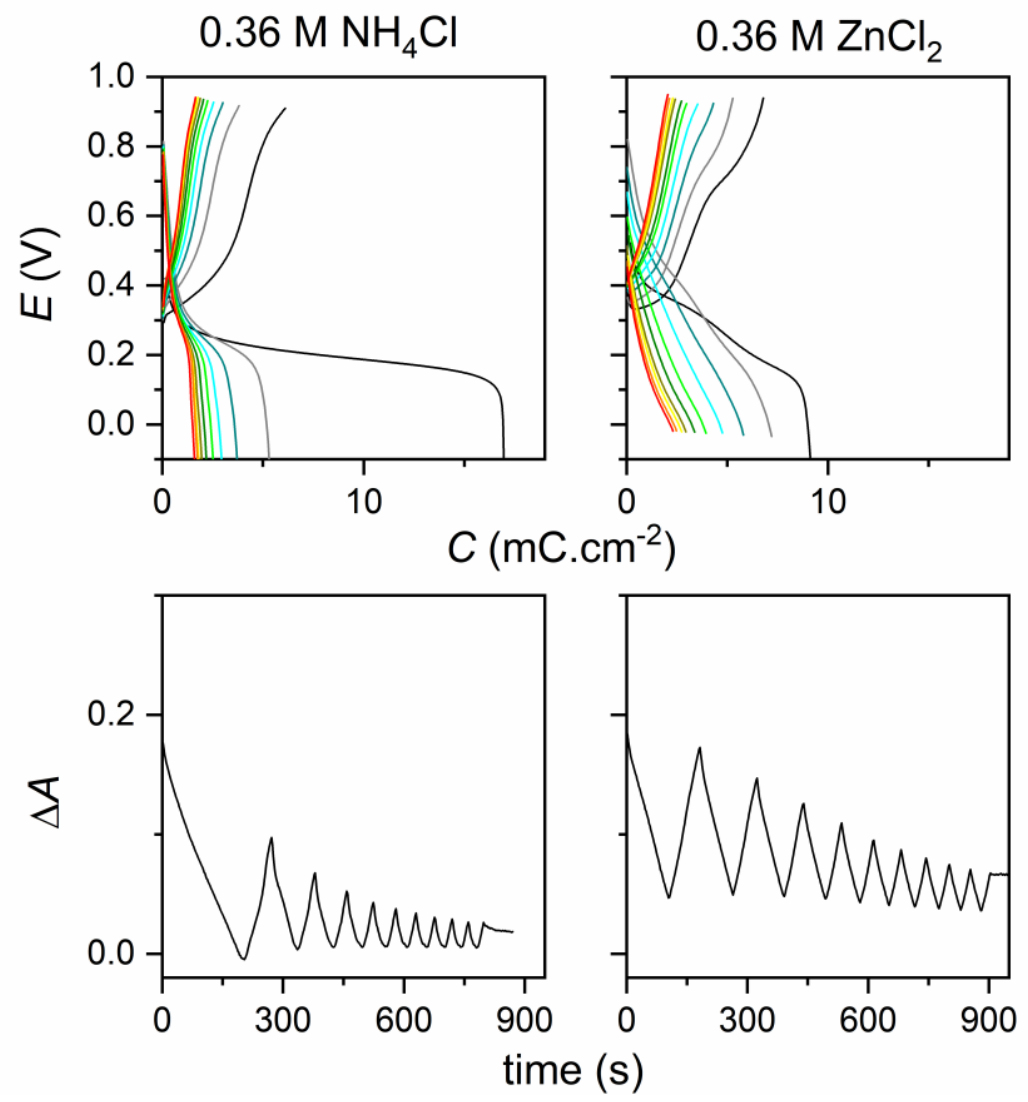

Figure S4. Continuous galvanostatic discharging/charging curves (10 cycles from black to red at $0.08 \mathrm{~mA} \cdot \mathrm{cm}^{-2}$ ) simultaneously recorded by (top) potentiometry and (bottom) absorptometry at as-electrodeposited $\mathrm{MnO}_{2}$ electrodes (loaded with $21.5 \pm 0.5 \mathrm{mC} \cdot \mathrm{cm}^{-2}$ ) in (left) $0.36 \mathrm{M} \mathrm{NH}_{4} \mathrm{Cl}$ and (right) $0.36 \mathrm{M} \mathrm{ZnCl}_{2}$ aqueous electrolyte (both adjusted to $\mathrm{pH} 5.0$ ). 


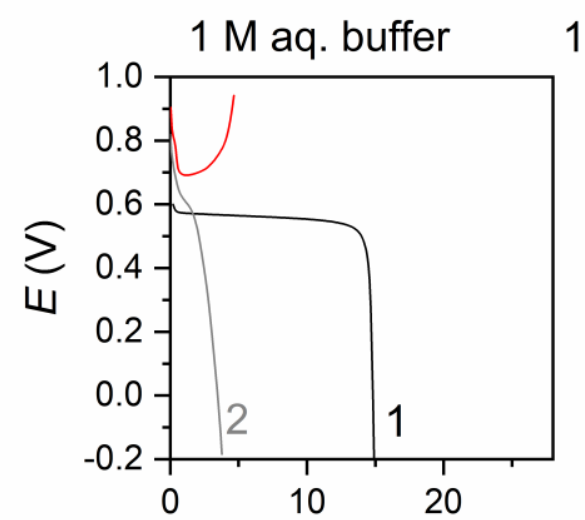

$1 \mathrm{M}$ aq. buffer $+0.1 \mathrm{MnCl}_{2}$
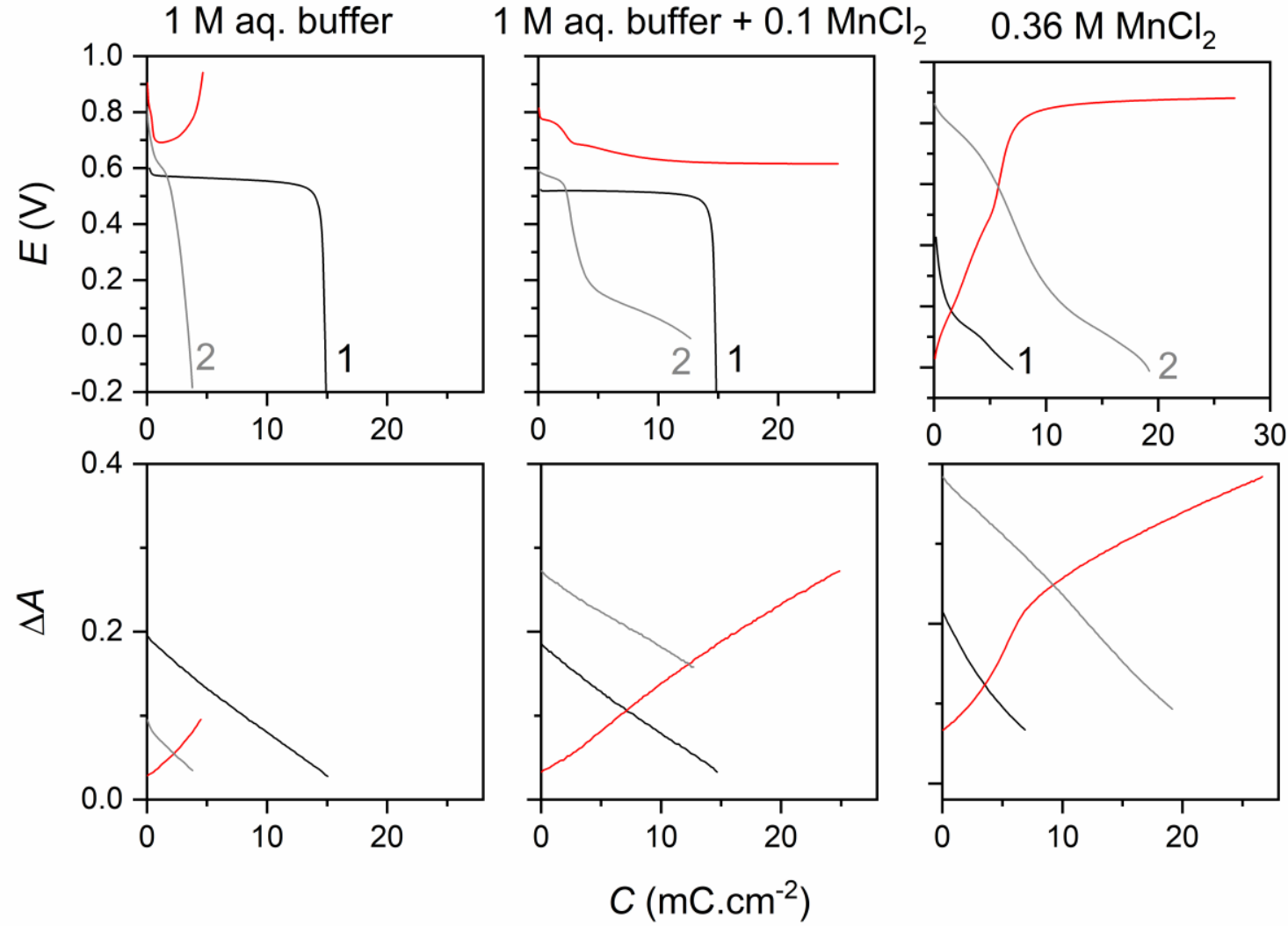

Figure S5. Galvanostatic discharging/charging curves (the first discharge is followed by a single charge/discharge cycle, rate: $0.08 \mathrm{~mA} \cdot \mathrm{cm}^{-2}$ ) simultaneously recorded by (top) potentiometry and (bottom) absorptiometry at as-electrodeposited $\mathrm{MnO}_{2}$ electrodes (loaded with $21.5 \pm 0.5 \mathrm{mC} \cdot \mathrm{cm}^{-2}$ ) in (left) $1 \mathrm{M}$ acetate buffer, (middle) $1 \mathrm{M}$ acetate buffer $+0.1 \mathrm{M}$ $\mathrm{MnCl}_{2}$, and (right) $0.36 \mathrm{M} \mathrm{MnCl}_{2}$ aqueous electrolyte (all adjusted at $\mathrm{pH}$ 5.0). The code color is as follow: (black) first discharge, (red) first charge, and (grey) second discharge.

In the absence of $\mathrm{MnCl}_{2}$, the charging potential rapidly increases up to the cut-off potential, an effect we can attribute to the low amount of $\mathrm{Mn}^{2+}$ that is released in the diffusion layer after the first discharge and which, during the subsequent charging step, is rapidly diluted far away into the bulk. On contrario, in presence of $\mathrm{MnCl}_{2}$ alone, the charging potential is continuously increased over a large potential window until it reaches an almost constant value $(\sim 0.87 \mathrm{~V})$. This huge potential variation can be attributed to a drastic local $\mathrm{pH}$ decrease (reaching a local value as low as 2.5 ) due to the large quantity of protons that are locally released during the electrodeposition step and also because of the absence of buffered conditions. Finally, unlike the two cases just mentioned, the charging potential does not drastically change in the buffered electrolyte with $\mathrm{MnCl}_{2}$ because there is no significant gradient of $\mathrm{pH}$ or $\left[\mathrm{Mn}^{2+}\right]$ that develop at the electrode interface. 

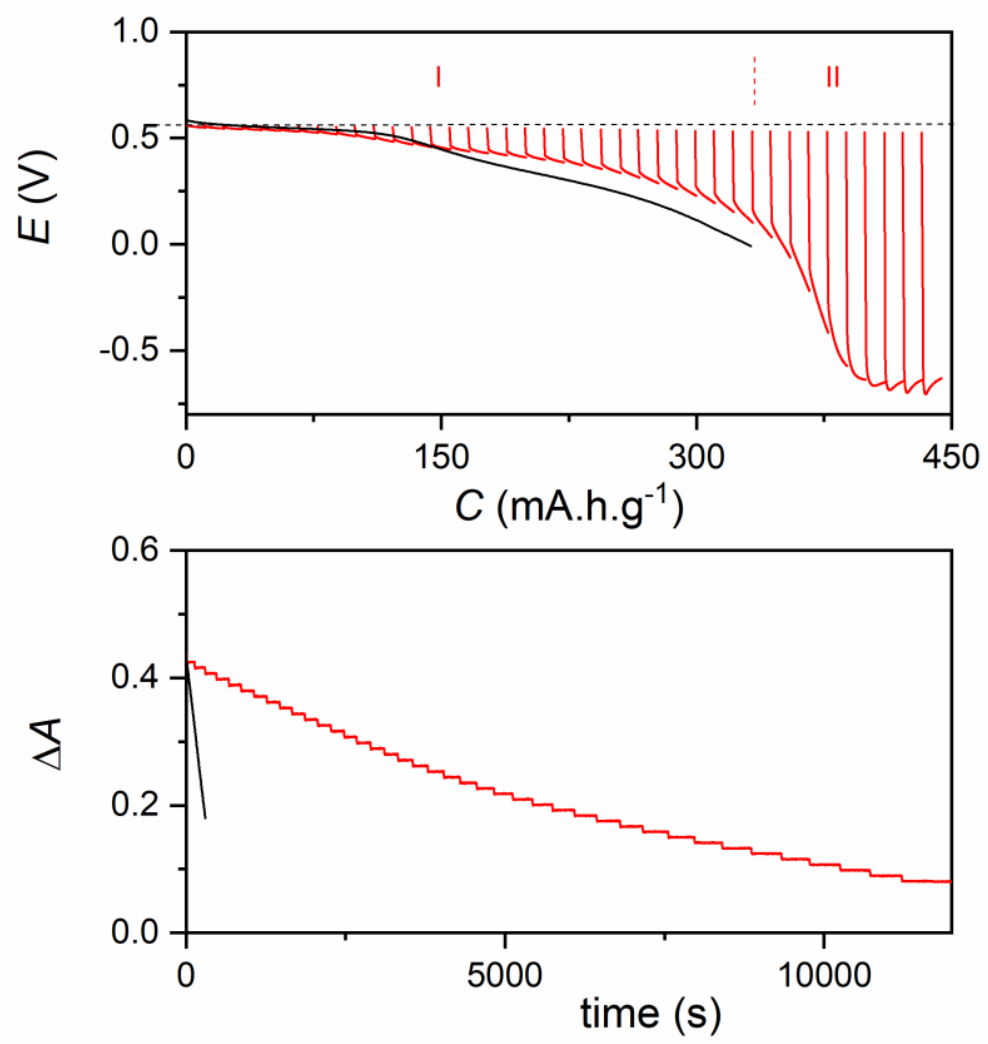

Figure S6. Galvanostatic discharge curves obtained under (black) continuous (300 s at 0.096 $\mathrm{mA} \cdot \mathrm{cm}^{-2}$ ) and (red) intermittent titration (40 discharge pulses of $10 \mathrm{~s}$ at $0.096 \mathrm{~mA} \cdot \mathrm{cm}^{-2}$ ) at a $\mathrm{MnO}_{2}$ thin-film ITO electrode (loaded with $11 \mu \mathrm{g} \cdot \mathrm{cm}^{-2} \mathrm{MnO}_{2}$ ) that was beforehand cycled 10 times in a $1 \mathrm{M}$ acetate buffer $(\mathrm{pH} 5.0)$ with $0.1 \mathrm{M} \mathrm{MnCl}_{2}$. The potentiometric (top) and absorptometric (bottom) traces were recorded simultaneously. For the intermittent titration, after each discharge pulse of $10 \mathrm{~s}$, the OCP was left to relax until to $\mathrm{dE} / \mathrm{dt}<10 \mu \mathrm{V} \cdot \mathrm{s}^{-1}$. 


\section{Supplementary Tables}

Table S1. XPS data for $\mathrm{MnO}_{2}$ films subjected (or not) to different galvanostatic cycles of discharge/charge in mild aqueous electrolytes.

\begin{tabular}{|c|c|c|c|c|c|c|c|}
\hline Sample & $\mathrm{Mn}$ & $\mathbf{K}$ & In & 0 & $\begin{array}{c}\text { Mn 3s } \\
\text { split } \\
\text { (eV) }\end{array}$ & $\underset{d}{A O S}$ & Formula ${ }^{e}$ \\
\hline $\begin{array}{l}\text { As- } \\
\text { electrodeposite } \\
\text { d }\end{array}$ & 21.2 & 1.90 & 0.14 & 46.2 & 4.63 & 3.72 & $\mathrm{Mn}^{\mathrm{IV}}{ }_{0.72} \mathrm{Mn}^{\mathrm{III}}{ }_{0.28} \mathrm{O}_{2} \mathrm{~K}_{0.09} \mathrm{H}_{0.19}$ \\
\hline $\begin{array}{l}\text { After a } 1^{\text {st }} \\
\text { discharge in } 1 \\
\mathrm{M} \mathrm{KCl}^{\mathrm{b}}\end{array}$ & 19.9 & 2.90 & 0.25 & 46.5 & 4.64 & 3.70 & $\mathrm{Mn}^{\mathrm{IV}}{ }_{0.70} \mathrm{Mn}^{\mathrm{III}}{ }_{0.30} \mathrm{O}_{2} \mathrm{~K}_{0.15} \mathrm{H}_{0.15}$ \\
\hline $\begin{array}{l}\text { After a } 1^{\text {st }} \\
\text { discharge in a } \\
\text { buffer }^{a, b}\end{array}$ & 11.4 & 0.50 & 6.32 & 42.5 & 4.71 & 3.63 & $\mathrm{Mn}^{\mathrm{IV}}{ }_{0.63} \mathrm{Mn}^{\mathrm{III}}{ }_{0.37} \mathrm{O}_{2} \mathrm{~K}_{0.04} \mathrm{H}_{0.33}$ \\
\hline 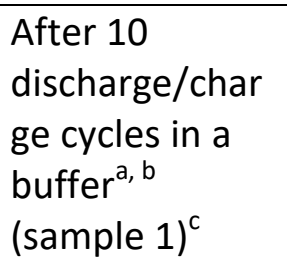 & 19.1 & 0.28 & 0.28 & 45.6 & 4.74 & 3.59 & $\mathrm{Mn}_{0.59}^{\mathrm{IV}} \mathrm{Mn}_{0.41}^{\mathrm{III}}{ }_{0.5} \mathrm{O}_{2} \mathrm{~K}_{0.015} \mathrm{H}_{0.4}$ \\
\hline $\begin{array}{l}\text { After } 10 \\
\text { discharge/char } \\
\text { ge cycles + one } \\
\text { last discharge } \\
\text { in a buffer, b } \\
(\text { sample } 2)^{\mathrm{c}}\end{array}$ & 17.8 & 0.38 & 1.4 & 45.1 & 4.86 & 3.45 & $\mathrm{Mn}^{\mathrm{IV}}{ }_{0.45} \mathrm{Mnn}^{\mathrm{III}}{ }_{0.55} \mathrm{O}_{2} \mathrm{~K}_{0.02} \mathrm{H}_{0.53}$ \\
\hline
\end{tabular}

${ }^{\mathrm{a}}$ The charge and discharge rate was fixed to $0.08 \mathrm{~mA} / \mathrm{cm}^{2}$.

${ }^{\mathrm{b}}$ The buffer solution refers here to a $1 \mathrm{M}$ acetate buffer $+0.1 \mathrm{M} \mathrm{MnCl}_{2}$ (pH 5.0).

${ }^{\mathrm{c}}$ The samples 1 and 2 are the same than those reported in Table S3.

${ }^{\mathrm{d}}$ Deduced from the XPS Mn 3s splitting values.

${ }^{\mathrm{e}}$ The fraction of potassium in the chemical formula is obtained from the relative atomic composition K/Mn.

For the sample 1, the morphology as well as chemical composition of the charged film is observed close to that reported for the as-electrodeposited $\mathrm{MnO}_{2}$ electrode with an AOS value of 3.6 for the Mn centers, still indicative of a mixed $\mathrm{Mn}^{3+} / \mathrm{Mn}^{4+}$ oxide layer. The final mass of $\mathrm{MnO}_{2}\left(m_{\mathrm{MnO}_{2}}^{f}\right)$ determined by ICP is $25.3 \mu \mathrm{g} \cdot \mathrm{cm}^{-2}$ (Table S3), almost doubled compared to the initial mass of $\mathrm{MnO}_{2}\left(m_{\mathrm{MnO}_{2}}^{i}\right)$. The sample 2 corresponds to an as-electrodeposited $\mathrm{MnO}_{2}$ electrode that was subjected to the same cycling experiment than sample 1 but with an additional discharge step at the end of the procedure. This discharged electrode is characterized by a much lower amount of Mn (Table S3) than with the sample 1, confirming that a large part of $\mathrm{MnO}_{2}$ has dissolved during the last galvanostatic discharge step. 
Table S2. Electrochemical data recovered from the galvanostatic cycling of different $\mathrm{MnO}_{2}$ electrodes in various mild aqueous electrolytes.

\begin{tabular}{|c|c|c|c|c|c|c|c|c|c|}
\hline \multirow[b]{2}{*}{$\begin{array}{l}\mathrm{MnO}_{2} \\
\text { phase }\end{array}$} & \multirow[b]{2}{*}{$\begin{array}{l}\text { Aqueous } \\
\text { Electrolyte }\end{array}$} & \multirow[b]{2}{*}{$\mathrm{pH}$} & \multirow[b]{2}{*}{$\begin{array}{c}\Delta \mathrm{BE} \\
\mathrm{Mn} \\
3 \mathrm{~s} \\
(\mathrm{eV})\end{array}$} & \multicolumn{3}{|c|}{ First discharge (single plateau) } & \multicolumn{2}{|c|}{$\begin{array}{l}\text { Reversible discharge at } \\
\text { high rates }\left(>1 \mathrm{~A} \cdot \mathrm{g}^{-1}\right)\end{array}$} & \multirow[b]{2}{*}{ Ref } \\
\hline & & & & $\begin{array}{l}\text { Capacity } \\
\left(\mathrm{mA} \cdot \mathrm{h} \cdot \mathrm{g}^{-1}\right)\end{array}$ & $\begin{array}{c}E_{\text {plateau }} \\
(\mathrm{V})^{\mathrm{a}}\end{array}$ & $\begin{array}{l}\text { Rate } \\
\left(A \cdot g^{-1}\right)\end{array}$ & $\begin{array}{l}\text { Maximal } \\
\text { Capacity } \\
\left(\mathrm{mA} \cdot \mathrm{h} \cdot \mathrm{g}^{-1}\right)\end{array}$ & $\begin{array}{l}\text { Rate } \\
\left(\mathrm{A} \cdot \mathrm{g}^{-1}\right)\end{array}$ & \\
\hline$\alpha-\mathrm{MnO}_{2}$ & $2 \mathrm{M} \mathrm{ZnSO}_{4}$ & $n a^{b}$ & na & $\begin{array}{l}210 \\
314\end{array}$ & $\begin{array}{l}0.29 \\
0.39\end{array}$ & $\begin{array}{c}0.062(C / 5) \\
0.0031(C / 100)\end{array}$ & $\begin{array}{l}113 \\
161\end{array}$ & $\begin{array}{c}3.0(10 C) \\
1.5(5 C)\end{array}$ & {$[518]$} \\
\hline$\beta-\mathrm{MnO}_{2}$ & $1 \mathrm{M} \mathrm{ZnSO}_{4}$ & na & na & 270 & 0.3 & 0.1 & & & [s19] \\
\hline $\begin{array}{l}\text { ramsdellite } \\
\mathrm{MnO}_{2}\end{array}$ & $2 \mathrm{M} \mathrm{ZnSO}_{4}$ & na & & 120 & 0.22 & 0.1 & & & {$[520]$} \\
\hline $\mathrm{cW}-\mathrm{MnO}_{2}$ & $1 \mathrm{M} \mathrm{ZnSO}_{4}$ & & & 350 & 0.39 & 0.1 & 154 & 3 & {$[521]$} \\
\hline $\mathrm{MnO}_{x} @ \mathrm{~N}-\mathrm{C}$ & $2 \mathrm{M} \mathrm{ZnSO}_{4}$ & na & na & 270 & 0.29 & 0.1 & & & $\lceil 522]$ \\
\hline $\begin{array}{l}\text { Amorphous } \\
\mathrm{MnO}_{2}\end{array}$ & $\begin{array}{l}1 \mathrm{M} \text { acetate } \\
\text { buffer }\end{array}$ & 5.0 & 4.65 & 404 & 0.56 & $7(23 C)$ & & & $\begin{array}{l}\text { This } \\
\text { work }\end{array}$ \\
\hline$\beta-\mathrm{MnO}_{2}$ & $\begin{array}{l}3 \mathrm{M} \mathrm{Zn}(\mathrm{OTf})_{2} \\
+0.1 \mathrm{M} \mathrm{Mn}(\mathrm{OTf})_{2}\end{array}$ & 3.8 & 4.7 & 307 & 0.12 & $(0.32 \mathrm{C})$ & $\begin{array}{l}115 \\
151 \\
188\end{array}$ & $\begin{array}{c}5(16.2 \mathrm{C}) \\
2.0(6.5 \mathrm{C}) \\
1.0 \\
(3.25 \mathrm{C})\end{array}$ & {$[523]$} \\
\hline$\alpha-\mathrm{MnO}_{2}$ & $\begin{array}{l}2 \mathrm{M} \mathrm{ZnSO}_{4} \\
+0.2 \mathrm{M} \mathrm{MnSO}_{4}\end{array}$ & 4.97 & 4.8 & 130 & 0.25 & 0.1 & $50-70$ & 1.885 & {$[513]$} \\
\hline PANI-MnO ${ }_{2}$ & $\begin{array}{l}2 \mathrm{M} \mathrm{ZnSO}_{4} \\
+0.1 \mathrm{M} \mathrm{MnSO}_{4}\end{array}$ & na & na & 260 & 0.4 & $0.05(0.16 \mathrm{C})$ & 160 & 1.5 & โ524] \\
\hline KMO & $\begin{array}{l}2 \mathrm{M} \mathrm{ZnSO}_{4} \\
+0.1 \mathrm{M} \mathrm{MnSO}_{4} \\
\end{array}$ & & 4.93 & 216 & & 0.1 & $\begin{array}{l}\sim 130 \\
\sim 100\end{array}$ & $\begin{array}{l}2 \\
1\end{array}$ & {$[525]$} \\
\hline$\delta-\mathrm{NMOH}$ & $\begin{array}{l}2 \mathrm{M} \mathrm{ZnSO}_{4} \\
+0.2 \mathrm{M} \mathrm{MnSO}_{4}\end{array}$ & na & 4.58 & & & & $\begin{array}{l}103 \\
134 \\
187 \\
\end{array}$ & $\begin{array}{l}6.16(20 C) \\
3.8(10 C) \\
1.23(4 C)\end{array}$ & {$[526]$} \\
\hline $\mathrm{MnO}_{x} @ \mathrm{~N}-\mathrm{C}$ & $\begin{array}{l}2 \mathrm{M} \mathrm{ZnSO}_{4} \\
+0.1 \mathrm{M} \mathrm{MnSO}_{4} \\
\end{array}$ & na & na & & & & 100 & 2 & {$[522]$} \\
\hline $\mathrm{O}_{\mathrm{d}}-\mathrm{MnO}_{2}$ & $\begin{array}{l}1 \mathrm{M} \mathrm{ZnSO}_{4} \\
+0.2 \mathrm{M} \mathrm{MnSO}_{4}\end{array}$ & & & & & & $\begin{array}{l}120 \\
180 \\
240\end{array}$ & $\begin{array}{l}5 \\
2 \\
1\end{array}$ & {$[56]$} \\
\hline $\begin{array}{l}\text { PEDOT- } \\
\mathrm{MnO}_{2}\end{array}$ & $\begin{array}{l}2 \mathrm{M} \mathrm{ZnCl}_{2} \\
+0.4 \mathrm{M} \mathrm{MnSO}_{4}\end{array}$ & & & & & & $\begin{array}{l}170 \\
200 \\
300 \\
\end{array}$ & $\begin{array}{l}5.6 \\
3.7 \\
1.1 \\
\end{array}$ & {$[527]$} \\
\hline $\begin{array}{l}\text { Amorphous } \\
\mathrm{MnO}_{2}\end{array}$ & $\begin{array}{l}1 \mathrm{M} \text { acetate } \\
\text { buffer } \\
+0.1 \mathrm{M} \mathrm{MnCl}_{2}\end{array}$ & 5.0 & 4.65 & $\begin{array}{c}385 \pm 20 \\
380 \pm 30 \\
385 \pm 20\end{array}$ & $\begin{array}{c}0.521 \\
0.52 \\
0.506\end{array}$ & $\begin{array}{c}1.25 \pm 0.16(4 C) \\
7.0 \pm 0.5(22 C) \\
15.0 \pm 1.4(49 C)\end{array}$ & $\begin{array}{l}274 \\
404 \\
450\end{array}$ & $\begin{array}{l}3.3 \\
1.5 \\
1.6\end{array}$ & $\begin{array}{l}\text { This } \\
\text { work }\end{array}$ \\
\hline
\end{tabular}

${ }^{a}$ All potentials were quoted vs. $\mathrm{Ag} / \mathrm{AgCl}$. The potentials from the literature (in italic) generally determined against a $\mathrm{Zn}$ electrode were corrected from the standard potential of $\mathrm{Zn}^{2+} / \mathrm{Zn}$, i.e. $E_{\mathrm{Zn}^{2+} / \mathrm{Zn}}^{0}=-0.96 \mathrm{~V} v$ s. $\mathrm{Ag} / \mathrm{AgCl}$.

${ }^{\mathrm{b}}$ Not available.

${ }^{\mathrm{c}}$ The C-rate value is defined here relative to the maximal theoretical capacity of $308 \mathrm{~mA} \cdot \mathrm{h} \cdot \mathrm{g}^{-1}$, which is the maximal capacity of $\mathrm{MnO}_{2}$ if we assume a process limited to a one-electron reaction (which is typically the assumption made in all cited references). 
Table S3. Quantitative data obtained for a set of $\mathrm{MnO}_{2}$-coated ITO electrodes (numbered from 1 to 11) cycled under different experimental conditions in a $1 \mathrm{M}$ acetate buffer (pH 5.0) in presence of $0.1 \mathrm{M} \mathrm{MnCl}_{2}$.

\begin{tabular}{|c|c|c|c|c|c|c|c|c|}
\hline Sample & $\begin{array}{c}m_{\mathrm{MnO2}}^{i} \\
\left(\mu \mathrm{g} / \mathrm{cm}^{2}\right)^{\mathrm{a}}\end{array}$ & $\begin{array}{l}\text { Number of galvanostatic } \\
\text { cycles (charging time) }\end{array}$ & $\begin{array}{l}\text { Rate } \\
(\mathrm{mA} / \\
\left.\mathrm{cm}^{2}\right)\end{array}$ & $\begin{array}{c}Q_{\text {total }}= \\
\sum_{i} Q_{i} \\
(\mathrm{mC} / \\
\left.\mathrm{cm}^{2}\right)^{\mathrm{b}}\end{array}$ & $\begin{array}{c}m_{\mathrm{MnO2}}^{f} \\
(\mu \mathrm{g} / \\
\left.\mathrm{cm}^{2}\right)^{\mathrm{c}}\end{array}$ & $\begin{array}{c}\text { Last } \\
\text { discharge } \\
\text { capacity } \\
(\mathrm{mA} \cdot \mathrm{h} / \mathrm{g})^{\mathrm{d}}\end{array}$ & $\begin{array}{l}\text { Final } \\
\text { rate } \\
(\mathrm{A} / \mathrm{g})^{\mathrm{e}}\end{array}$ & $\begin{array}{c}\text { Electro- } \\
\text { active } \\
\mathrm{MnO}_{2} \\
(\%)^{\mathrm{f}}\end{array}$ \\
\hline 1 & 11 & 10 (300s) & 0.083 & 22.5 & 25.3 & 274 & 3.3 & 51 \\
\hline 2 & 10.6 & 10 (300s) + 1 discharge & 0.08 & -4.5 & 10.8 & & & \\
\hline 3 & 11.4 & 10 (300s) + 5 (1000s) & 0.083 & 82.3 & 57 & 404 & 1.5 & 75 \\
\hline 4 & 11.6 & $\begin{array}{l}10(300 s)+5(1000 s)+1 \\
\text { discharge }\end{array}$ & 0.085 & 3.4 & 19.1 & & & \\
\hline 5 & 10.95 & $\begin{array}{l}10 \text { (incremental increase } \\
\text { from } 100 \text { to } 1000 \mathrm{~s} \text { ) }\end{array}$ & 0.092 & 81.5 & 56.7 & 450 & 1.6 & 84 \\
\hline $6-1$ & 11.5 & 10 (150s) & 0.16 & 32.2 & 18.6 & 223 & 8.6 & 41 \\
\hline $6-I I$ & 10.3 & 10 (150s) & 0.16 & 27 & 24.7 & 264 & 6.5 & 49 \\
\hline $6-111$ & 12 & 10 (150s) & 0.18 & 30.3 & 26.2 & 281 & 6.9 & 52 \\
\hline $7-1$ & 11 & 10 (150s) + 1 discharge & 0.15 & 7.4 & 15.7 & & & \\
\hline $7-11$ & 11.8 & 10 (150s) + 1 discharge & 0.18 & 4.9 & 12.7 & & & \\
\hline $7-111$ & 10 & 10 (150s) + 1 discharge & 0.16 & -1.4 & 8.1 & & & \\
\hline $8-1$ & 11 & $10(150 s)+5(500 s)$ & 0.17 & 150.4 & 82.5 & 286 & 2.1 & 53 \\
\hline $8-I I$ & 11 & $10(150 s)+5(500 s)$ & 0.16 & 115.2 & 71.5 & 310 & 2.2 & 57 \\
\hline $9-1$ & 10.55 & $\begin{array}{l}10(150 s)+5(500 s)+1 \\
\text { discharge }\end{array}$ & 0.16 & 52.5 & 41 & & & \\
\hline $9-11$ & 10.75 & $\begin{array}{l}10 \text { (150s) + } 5 \text { (500s) + } 1 \\
\text { discharge }\end{array}$ & 0.16 & 26.7 & 35.6 & & & \\
\hline
\end{tabular}

${ }^{\mathrm{a}}$ Determined from the charge passed during the $\mathrm{MnO}_{2}$ film preparation, see Experimental Section.

${ }^{\mathrm{b}}$ Cumulated charge as defined in the Experimental Section.

${ }^{\mathrm{c}}$ Determined by ICP after electrode cycling.

${ }^{\mathrm{d}}$ Estimated on the basis of the last discharge and the final mass of $\mathrm{MnO}_{2}$.

${ }^{\mathrm{e}}$ Based on the final mass of electrodeposited $\mathrm{MnO}_{2}$.

${ }^{\mathrm{f}}$ Calculated on the basis of an average experimental gravimetric capacity of $540 \mathrm{~mA} \cdot \mathrm{h} \cdot \mathrm{g}^{-1}$.

All of the $\mathrm{MnO}_{2}$ electrodes were first loaded with an approximately same amount of $\mathrm{MnO}_{2}$ using the electrodeposition process described in the Experimental Section (this amount is reported in the 2nd column of Table S3). The $\mathrm{MnO}_{2}$ electrodes were then each independently galvanostatically discharged/charged for a number of cycles in a $1 \mathrm{M}$ acetate buffer ( $\mathrm{pH} 5.0$ ) containing $0.1 \mathrm{M} \mathrm{MnCl}_{2}$. The charging time (in s) is specified in column 3, whereas the discharged time was fixed by the cut-off potential of $0.0 \mathrm{~V}$. At the end of the cycling, the amount of $\mathrm{MnO}_{2}$ present on each ITO electrode was analyzed by ICP (see 6th column of Table S3). Charged electrodes (obtained after a last charging step) are highlighted in yellow, whereas discharged electrodes (obtained after a last discharging step until reaching the cut-off value) are highlighted in blue. 


\section{References}

[S1] D. L. Parkhurst, in Chem. Model. Aqueous Syst. II, American Chemical Society, 1990, pp. 3-30.

[S2] V. R. Galakhov, M. Demeter, S. Bartkowski, M. Neumann, N. A. Ovechkina, E. Z. Kurmaev, N. I. Lobachevskaya, Y. M. Mukovskii, J. Mitchell, D. L. Ederer, Phys. Rev. B - Condens. Matter Mater. Phys. 2002, 65, 1.

[S3] M. Sun, B. Lan, T. Lin, G. Cheng, F. Ye, L. Yu, X. Cheng, X. Zheng, CrystEngComm 2013, 15, 7010.

[S4] S. Chou, F. Cheng, J. Chen, J. Power Sources 2006, 162, 727.

[S5] M. Huynh, D. K. Bediako, Y. Liu, D. G. Nocera, J. Phys. Chem. C 2014, 118, 17142.

[S6] T. Xiong, Z. G. Yu, H. Wu, Y. Du, Q. Xie, J. Chen, Y.-W. W. Zhang, S. J. Pennycook, W. S. V. Lee, J. Xue, Adv. Energy Mater. 2019, 9, 1803815.

[S7] A. Rafique, A. Massa, M. Fontana, S. Bianco, A. Chiodoni, C. F. Pirri, S. Hernández, A. Lamberti, ACS Appl. Mater. Interfaces 2017, 9, 28386.

[S8] Y. Saito, M. Meguro, M. Ashizawa, K. Waki, R. Yuksel, H. E. Unalan, H. Matsumoto, RSC Adv. 2017, 7, 12351.

[S9] S. L. Kuo, N. L. Wu, J. Electrochem. Soc. 2006, 153, 1317.

[S10] W. Yan, J. Y. Kim, W. Xing, K. C. Donavan, T. Ayvazian, R. M. Penner, Chem. Mater. 2012, $24,2382$.

[S11] K. W. Nam, M. G. Kim, K. B. Kim, J. Phys. Chem. C 2007, 111, 749.

[S12] D. Chao, W. Zhou, C. Ye, Q. Zhang, Y. Chen, L. Gu, K. Davey, S. Z. Qiao, Angew. Chemie - Int. Ed. 2019, 7823.

[S13] W. Sun, F. Wang, S. Hou, C. Yang, X. Fan, Z. Ma, T. Gao, F. Han, R. Hu, M. Zhu, C. Wang, J. Am. Chem. Soc. 2017, 139, 9775.

[S14] P. Ruetschi, J. Electrochem. Soc. 1984, 131, 2737.

[S15] P. Ruetschi, R. Giovanoli, J. Electrochem. Soc. 1988, 135, 2663.

[S16] W. Yan, T. Ayvazian, J. Kim, Y. Liu, K. C. Donavan, W. Xing, Y. Yang, J. C. Hemminger, R. M. Penner, ACS Nano 2011, 5, 8275 .

[S17] M. Chigane, M. Ishikawa, J. Electrochem. Soc. 2000, 147, 2246.

[S18] H. Pan, Y. Shao, P. Yan, Y. Cheng, K. S. Han, Z. Nie, C. Wang, J. Yang, X. Li, P. Bhattacharya, K. T. Mueller, J. Liu, Nat. Energy 2016, 1, 16039.

[S19] S. Islam, M. H. Alfaruqi, V. Mathew, J. Song, S. Kim, S. Kim, J. Jo, J. P. Baboo, D. T. Pham, D. Y. Putro, Y. K. Sun, J. Kim, J. Mater. Chem. A 2017, 5, 23299.

[S20] I. Stoševski, A. Bonakdarpour, F. Cuadra, D. P. Wilkinson, Chem. Commun. 2019, 55, 2082.

[S21] K. W. Nam, H. Kim, J. H. Choi, J. W. Choi, Energy Environ. Sci. 2019, 12, 1999.

[S22] Y. Fu, Q. Wei, G. Zhang, X. Wang, J. Zhang, Y. Hu, D. Wang, L. Zuin, T. Zhou, Y. Wu, S. Sun, Adv. Energy Mater. 2018, 8, 1801445.

[S23] N. Zhang, F. Cheng, J. Liu, L. Wang, X. Long, X. Liu, F. Li, J. Chen, Nat. Commun. 2017, 8, 405.

[S24] J. Huang, X. Dong, Y. Wang, Y. Xia, M. Hou, Y. Liu, Z. Wang, Nat. Commun. 2018, 9, 1.

[S25] G. Fang, C. Zhu, M. Chen, J. Zhou, B. Tang, X. Cao, X. Zheng, A. Pan, S. Liang, Adv. Funct. Mater. 2019, 29, 1808375.

[S26] D. Wang, L. Wang, G. Liang, H. Li, Z. Liu, Z. Tang, J. Liang, C. Zhi, ACS Nano 2019, 13, 10643.

[S27] Y. Zeng, X. Zhang, Y. Meng, M. Yu, J. Yi, Y. Wu, X. Lu, Y. Tong, Adv. Mater. 2017, $29,1$. 